\title{
Learning new word meanings from story reading: The benefit of immediate testing
}

\author{
Rachael C Hulme ${ }^{\text {Corresp., }, 2}$, Jennifer M Rodd ${ }^{1}$ \\ 1 Department of Experimental Psychology, University College London, University of London, London, United Kingdom \\ 2 Aston Institute of Health and Neurodevelopment and School of Psychology, Aston University, Birmingham, United Kingdom \\ Corresponding Author: Rachael C Hulme \\ Email address: rachael.hulme.14@ucl.ac.uk
}

This study investigated how word meanings can be learned from natural story reading. Three experiments with adult participants compared naturalistic incidental learning with intentional learning of new meanings for familiar words, and examined the role of immediate tests in maintaining memory of new word meanings. In Experiment 1, participants learned new meanings for familiar words through incidental (story reading) and intentional (definition training task) conditions. Memory was tested with cued recall of meanings and multiple-choice meaning-to-word matching immediately and 24 hours later. Results for both measures showed higher accuracy for intentional learning, which was also more time efficient than incidental learning. However, there was reasonably good learning from both methods, and items learned incidentally through stories appeared less susceptible to forgetting over 24 hours. It was possible that retrieval practice at the immediate test may have aided learning and improved memory of new word meanings 24 hours later, especially for the incidental story reading condition. Two preregistered experiments then examined the role of immediate testing in long-term retention of new meanings for familiar words. There was a strong testing effect for word meanings learned through intentional and incidental conditions (Experiment 2), which was non-significantly larger for items learned incidentally through stories. Both cued recall and multiple-choice tests were each individually sufficient to enhance retention compared to having no immediate test (Experiment 3), with a larger learning boost from multiple-choice. This research emphasises (i) the resilience of word meanings learned incidentally through stories and (ii) the key role that testing can play in boosting vocabulary learning from story reading. 
2

3

4

Learning new word meanings from story reading:

\section{The benefit of immediate testing}

9 Rachael C. Hulme $e^{1,2}$ and Jennifer M. Rodd ${ }^{1}$

$10{ }^{1}$ Department of Experimental Psychology, University College London, London, UK

$11{ }^{2}$ Aston Institute of Health and Neurodevelopment and School of Psychology, Aston University,

12 Birmingham, UK

13

14 Corresponding author:

15 Rachael Hulme ${ }^{1,2}$

16 Email address: rachael.hulme.14@ucl.ac.uk 


\section{Abstract}

This study investigated how word meanings can be learned from natural story reading.

19 Three experiments with adult participants compared naturalistic incidental learning with

20 intentional learning of new meanings for familiar words, and examined the role of immediate

21 tests in maintaining memory of new word meanings. In Experiment 1, participants learned new

22 meanings for familiar words through incidental (story reading) and intentional (definition

23 training task) conditions. Memory was tested with cued recall of meanings and multiple-choice

24 meaning-to-word matching immediately and 24 hours later. Results for both measures showed

25 higher accuracy for intentional learning, which was also more time efficient than incidental

26 learning. However, there was reasonably good learning from both methods, and items learned

27 incidentally through stories appeared less susceptible to forgetting over 24 hours. It was possible

28 that retrieval practice at the immediate test may have aided learning and improved memory of

29 new word meanings 24 hours later, especially for the incidental story reading condition. Two

30 preregistered experiments then examined the role of immediate testing in long-term retention of

31 new meanings for familiar words. There was a strong testing effect for word meanings learned

32 through intentional and incidental conditions (Experiment 2), which was non-significantly larger

33 for items learned incidentally through stories. Both cued recall and multiple-choice tests were

34 each individually sufficient to enhance retention compared to having no immediate test

35 (Experiment 3), with a larger learning boost from multiple-choice. This research emphasises (i)

36 the resilience of word meanings learned incidentally through stories and (ii) the key role that

37 testing can play in boosting vocabulary learning from story reading.

Keywords 
40 incidental learning; intentional learning; testing effect; homonyms; story reading 
41

\section{Introduction}

Recent research emphasises the importance of good vocabulary knowledge: individuals

with better vocabulary perform better on reading comprehension tests, and have better

educational outcomes (Armstrong et al., 2017; Cain \& Oakhill, 2014). Despite widespread

acceptance that incidental learning from natural linguistic environments (e.g., conversations, books, TV) is the main source of vocabulary learning (Batterink \& Neville, 2011; Nagy et al., 1985, 1987), most studies of vocabulary learning in adults use highly artificial stimuli, tasks, and learning conditions. The current experiments focus on learning from naturalistic fiction stories that are read by participants in their native language without any explicit instructions to learn the new vocabulary that the stories contain. We investigate the extent to which people's ability to retain newly-learned word meanings over time is improved by requiring them to retrieve these word meanings during the intervening period between encoding and a later test. The presence of such a beneficial "testing effect" has been well established through studies of explicit, intentional learning (for reviews, see Roediger \& Butler, 2011; Rowland, 2014), but it is unclear whether retrieval would similarly enhance memory for vocabulary learned under more naturalistic, incidental learning conditions. The finding that vocabulary learning from naturalistic materials could be significantly boosted by a brief episode of testing could provide a simple approach to boosting vocabulary gains in real-world settings.

Incidental vocabulary learning is defined as learning words and their meanings whilst engaged in another activity such as listening or reading for comprehension (Hulstijn, 2003). A real-life context in which adults often learn new words and their meanings is when reading fiction, due to the rich and varied situations that are often depicted (Nation, 2017). Studies of word learning from stories by adult native-language (L1) readers have adopted highly naturalistic 
64 methods by using either authentic texts (Godfroid et al., 2017; Saragi et al., 1978) or texts

65 modified or written specifically for the purposes of the studies (Batterink \& Neville, 2011;

66 Henderson et al., 2015; Pellicer-Sánchez, 2016). In these studies participants read works of

67 fiction with the primary focus being on comprehension, with vocabulary learning as a by-

68 product. To discourage intentional learning strategies, readers are not given any instruction to

69 learn new vocabulary encountered in a text and are not informed that their memory will later be 70 tested.

The current study uses a paradigm developed by Hulme et al. (2019) in which

72 participants encounter artificial new meanings for familiar English words in the context of custom-written short stories (e.g., learning that a foam is a type of safe concealed within a piece of furniture). This ability to learn new word meanings is a key aspect of vocabulary development: around $80 \%$ of common English words have more than one definition (Rodd, 2018; Rodd et al., 2002). Adults often learn additional word senses/meanings, and continue to update their knowledge of these words throughout their adult lives (Betts et al., 2018; Gaskell et al., 2019; Gilbert et al., 2018, 2021; Rodd et al., 2013). Examples of reasons why adults learn new meanings for familiar words include language evolution (e.g., the internet-related meaning of "troll"), or learning a new subject or activity (e.g., the sailing term "boom"; Eligio \& Kaschak,

81 2021; Rodd et al., 2012, 2016). New meanings are often learned when reading stories, especially

82 of the science fiction or fantasy genres (e.g., a "galleon" is a coin of the wizarding currency in

83 the Harry Potter series of novels by J. K. Rowling). Recently, Fang et al. (2016) proposed that

84 learning new meanings for familiar words is a dual-phase process whereby familiarity with the

85 word form may facilitate learning with the initial encounters, but inhibition due to meaning 
86 competition begins to take effect after subsequent exposures to the newly ambiguous word

87 (Maciejewski et al., 2020; Maciejewski \& Klepousniotou, 2020; see Rodd, 2020 for review). Hulme et al. (2019) found that participants were able to recall the new meanings for the

89 known words reasonably well (38.5\% correct) after only two exposures in a story context, with a

90 linear increase in meaning recall with additional exposures (63.5\% correct after eight exposures).

91 Interestingly, Hulme et al.'s (2019) participants showed no significant forgetting of the new

92 meanings they had learned at a surprise test one week later across all of the exposure conditions.

93 The current study further examines this incidental form of word learning by (i) comparing

94 performance to a more explicit learning condition and (ii) investigating the potential boost to performance from an immediate test of knowledge after training. Understanding how these two

96 factors impact on long-term retention of vocabulary will provide a critical foundation for 97 subsequent development of interventions to boost vocabulary acquisition.

98 The conditions of initial vocabulary acquisition (incidental or intentional) prompt

99 different types of information processing, which may affect retention of word meanings in

100 different ways. Vocabulary learned under intentional conditions may be retained better over time

101 because more attention is directly focussed on encoding the word meanings, and the meaning is

102 made more explicit. This more strategic processing might be particularly important for

103 facilitating access to prior knowledge in the case of learning new ambiguous words where the

104 learner may benefit from more explicitly noticing the mismatch between the familiar word

105 meaning and the new meaning. In contrast, incidental vocabulary learning from story reading

106 may benefit from the rich and informative story contexts (Webb, 2008), and it has been

107 suggested that the increased mental effort required to encode new word meanings inferred from

108 context may be beneficial for retention (Hulstijn, 1992). However, it is also important to consider 
109 that while incidental vocabulary learning is usually contextualised (with words embedded in

110 informative contexts from which meaning is inferred), intentional vocabulary learning may also

111 involve context, or it can be decontextualised.

112 The consensus from the literature on adult second language (L2) learning (e.g., Hulstijn,

113 1992; Lehmann, 2007; Peters et al., 2009), and research with teenagers learning L1 vocabulary

114 (Konopak et al., 1987) is that intentional learning offers greater vocabulary gains and is more

115 efficient than incidental learning. However, some other studies have found little difference

116 (Lehmann, 2007), or even an efficiency advantage in terms of words learned per minute for

117 incidental learning (Mason \& Krashen, 2004). Several recent studies with adult L1 readers have

118 also found good levels of native language vocabulary acquisition from reading alone (Batterink

119 \& Neville, 2011; Godfroid et al., 2017; Pellicer-Sánchez, 2016). A further key factor that could

120 differ between vocabulary acquisition under incidental and intentional learning conditions is the

121 impact of testing on subsequent retention.

122 The "testing effect" refers to the finding that testing memory following training can

123 enhance long-term retention, as the additional retrieval practice at test affords an opportunity for

124 further learning (for reviews, see Roediger \& Butler, 2011; Rowland, 2014). The effect has been

125 demonstrated as robust in various experiments using explicit, intentional learning conditions.

126 However, it is unclear whether the testing effect would provide a similar benefit for vocabulary

127 learned under incidental learning conditions. Given that the vast majority of native language

128 words and their meanings are learned incidentally (Batterink \& Neville, 2011), it is important to

129 examine the impact of the testing effect under such learning conditions. If the presence of a

130 quick, immediate vocabulary test can indeed enhance learning/retention for incidentally learned 
131 vocabulary this could potentially provide a simple method for boosting vocabulary gains from

132 story reading, especially within educational settings.

133 In vocabulary learning research, retrieval practice has been shown to lead to better

134 retention of new words over time with adults learning second language (L2) vocabulary under

135 intentional conditions (e.g., Fritz et al., 2007; Karpicke \& Roediger, 2008; van den Broek et al.,

136 2013, 2018), and similarly with children learning novel L1 words (Goossens et al., 2014;

137 Goossens et al., 2014; Toppino \& Cohen, 2009). The testing effect further enhances retention

138 when feedback is provided on performance on the immediate test (e.g., Pashler et al., 2005), but

139 retrieval practice is often beneficial even in the absence of any feedback (Roediger \& Butler,

140 2011). The precise neurocognitive mechanism underlying the testing effect is currently unclear,

141 but it has recently been suggested that retrieval practice may provide a fast track to consolidation

142 of new information through the online reactivation of related knowledge (Antony et al., 2017;

143 see the General Discussion for further discussion).

144 It is possible that different learning conditions preceding retrieval practice could

145 moderate the testing effect for various reasons. For example, it is thought that semantic

146 elaboration may be key to the neurocognitive mechanism underlying the testing effect

147 (Carpenter, 2009). If this is the case, then the richer story contexts during encoding in the

148 incidental condition could provide more fertile material for semantic elaboration, thus enhancing

149 the testing effect. On the other hand, research has suggested that the benefits of retrieval practice

150 are greater when retrieval success during practice is high (Rowland, 2014). Therefore, if

151 intentional learning is more effective than incidental learning then this could lead to a stronger

152 testing effect following encoding under intentional learning conditions. 

under a variety of conditions (e.g., Butler, 2010; Karpicke \& Roediger, 2008; Roediger \&

155 Karpicke, 2006a; van den Broek et al., 2013), although little research has compared across

156 different learning conditions. One study (Goossens et al., 2014) directly compared the impact of

157 testing on children's learning of novel L1 vocabulary from a story context to learning new words

158 in isolation. Results showed that children correctly recalled more word meanings that had been

159 tested, and children in the word list condition remembered the word meanings better overall than

160 those in the story condition. The testing effect was also slightly stronger for the word list

161 condition. However, learning was not incidental in either condition in this study, and children

162 who heard the story also had the meanings of the words explained to them. Furthermore, the

163 participants in this study were children (aged 8-11), and results may differ for adults whose

164 advanced language skills and vocabulary knowledge make them better equipped to learn more

165 successfully from the richer contexts that stories provide. It therefore remains to be seen whether

166 the benefit of retrieval practice would differ for the learning of new word meanings acquired

167 solely under incidental conditions in a story context, as compared with learning under intentional 168 conditions.

\section{Experiment 1: Incidental versus intentional learning}

171 Experiment 1 compared the story-reading method designed by Hulme et al. (2019) for

172 studying incidental learning of new meanings for familiar words with a more conventional,

173 intentional training procedure. This provided a baseline assessment of how well adults are able to

174 learn new word meanings from a naturalistic incidental learning paradigm as compared to a more

175 conventional explicit approach to vocabulary learning, and provided a foundation for the 
176 subsequent preregistered experiments to investigate learning performance in more detail.

177 Specifically, Experiments 2 and 3 will follow up on Experiment 1 to examine whether the

178 inclusion of an immediate test of new vocabulary knowledge aids learning and improves

179 memory of new word meanings 24 hours later. This may be especially pertinent for vocabulary

180 acquired through incidental learning conditions as it may prompt participants to adopt different

181 information processing strategies after initial acquisition.

182 In Experiment 1 participants learned novel meanings for existing unambiguous words

183 through both incidental story-reading (as in the study by Hulme et al., 2019) and a newly

184 developed intentional task-based learning procedure, with the same number of exposures to

185 items. The two learning conditions were implemented based on typical paradigms for these two

186 types of learning. However, it is important to note that there are multiple differences in the

187 learning experience, for example only the incidental learning paradigm required participants to

188 infer meaning from context. While it is more common for incidental learning to be

189 contextualised in this way, some intentional learning paradigms also involve contextualised

190 learning (see for example: van den Broek et al., 2018). The stories used in the incidental learning

191 condition combined naturalistic elements of authentic texts (Godfroid et al., 2017; Saragi et al.,

192 1978) with precise experimental control over the exposure to items within the text (Batterink \&

193 Neville, 2011; Pellicer-Sánchez, 2016). Items were encountered incidentally within the stories

194 that participants read for comprehension and were central to the narrative.

195 Participants' knowledge of the new meanings for all items was assessed first through

196 cued recall, and second through a multiple-choice meaning-to-word matching test. The recall

197 measure is a harder test with fewer cues to help retrieve memories of the new word meanings,

198 while the multiple-choice test is a recognition measure with more cues and is therefore the easier 
199 of the two tests. Using two tests of learning with different difficulty levels allowed us to reduce

200 the possibility of floor/ceiling effects. The tests were administered both immediately after

201 learning, and again 24 hours later to assess longer-term retention. Based on the previous

202 research, we predicted that learning of new word meanings would be better for intentional

203 learning conditions, although we expected reasonably good vocabulary learning for the

204 incidental learning conditions in line with the findings of Hulme et al. (2019). We also predicted 205 there would be little forgetting after 24 hours, although we had no specific predictions as to 206 whether this would differ for new word meanings acquired through incidental or intentional 207 learning conditions. Our predictions were the same for the cued recall test the and multiple208 choice meaning-to-word matching test.

209 The materials, data, and analysis scripts for Experiment 1 can be found on the Open

210 Science Framework (OSF; https://osf.io/k32tw). For all experiments we report all measures, 211 conditions, data exclusions, and how we established the sample size.

\section{Method}

$214 \quad$ Participants.

215 We aimed to recruit 40 participants for Experiment 1. The study by Hulme et al. (2019)

216 included 64 participants who were trained on four items (one per exposure condition) in one of

21716 experiment versions (four participants per version). In this study participants were trained on

218 eight items (four items per learning condition) in one of eight experiment versions (five

219 participants per version), we therefore expected power to be comparable to that of Hulme et al.

220 (2019). Forty participants were included in the experiment (age: $M=30.1$ years, $S D=7.1 ; 23$

221 female). Participants were recruited through the Prolific recruitment website (Damer \& Bradley, 
222 2014) using pre-screening criteria. They gave their informed consent before taking part (by

223 means of ticking boxes in the online consent form). The UCL Experimental Psychology Ethics

224 Committee granted ethical approval for the research (Ref: EP/2017/009). Participants were

225 invited to take part if they were a current UK resident, a monolingual native speaker of British

226 English, and had no diagnosis of reading or language impairments. They were paid for their

227 participation in the first session of the experiment (£5) and additionally upon completion of the

228 second session 24 hours later (£1). Of the 40 participants who completed the first session, 31 also

229 completed the 24-hour follow-up session on time (77.5\%). One additional participant was

230 excluded from the second session due to completing it after the deadline (within six hours of

231 receiving the invitation for the follow-up session).

232 Five additional participants were excluded from the study - two were not monolingual

233 native British English speakers, and three got more than one of the multiple-choice

234 comprehension questions wrong when reading the stories (see Procedure). Excluded participants

235 were replaced during recruitment.

236

237

\section{Materials.}

238

239

240

Novel word meanings.

241 new meanings were unrelated to the existing meanings of the words, and described hypothetical

242 innovations, discoveries, and inventions. There was one definition sentence for each of the

243 stimulus words that described its new meaning, for example: "A foam is a safe that is

244 incorporated into a piece of furniture with a wooden panel concealing the key lock, and each is 
245 individually handcrafted so that no intruders are able to recognize the chief use of the furniture."

246 The sentences were matched for length $(M=32.9$ words, $S D=3.7)$. Each new meaning had three

247 distinguishing semantic features to maintain a similar level of complexity for each new concept,

248 for example, for foam: "a safe inside a piece of furniture," "has a hidden key lock," and

249 “individually handcrafted to fool intruders." The words and their meanings were incorporated

250 into story narratives for the incidental learning condition, and the definition sentences were

251 presented to participants in the definition reading phase of the intentional learning condition.

252 Three shorter paraphrased excerpts of the definition sentences were created for use in the

253 two-alternative multiple-choice training task (length: $M=11.29$ words; $S D=2.13$ ), with each

254 sentence describing a semantic feature of that item (e.g., for "foam": "A secure place to store

255 valuables within an item of furniture."; "A safe with a wooden panel disguising the key lock.";

256 and "A bespoke handcrafted piece of furniture containing a safe hidden from intruders.").

257 Paraphrased versions were used to encourage participants to read the whole sentence each time,

258 rather than relying on recognition of the first words (see Table S2 for the short sentences:

259 https://osf.io/m4wxa).

260 An additional longer paraphrased version of each of the definition sentences (which were

261 used in the test of cued recall of word forms in Hulme et al.'s (2019) study) were used in the

262 multiple-choice test at the end of this experiment (see Table S3 for the sentences used for the

263 multiple-choice test: https://osf.io/m4wxa).

Short stories.

The four short stories from Hulme et al.'s (2019) study were used to present stimuli to

267 participants in the incidental learning condition in this experiment (see the Supplementary 
268 Materials for the stories: https://osf.io/m4wxa). These stories (ranging 2307-2446 words in

269 length) were written by a professional children's author (Story 1: Pink Candy Dream), and an

270 unpublished author (Story 2: Prisons, Story 3: Reflections upon a Tribe, and Story 4: The Island

271 and Elsewhere), and were designed to be interesting for an adult audience. Each story

272 incorporated four of the items in the context of their new meanings, with each item appearing a

273 total of eight times at naturally distributed positions within a story. No item appeared in more

274 than four consecutive sentences, and all items occurred on at least two different pages of the

275 story. On the first presentation of a stimulus word, sufficient information was given to allow the

276 reader to derive the new meaning from the context from the first exposure, for example, "'Yes,' I

277 murmured, breathing again. 'I knew it! It's a foam.' The ornate chaise longue was no ordinary

278 piece of furniture but concealed a built-in safe with an intricate key-operated locking system."

279 The amount of information about each new meaning in subsequent exposures varied naturally

280 with the story narratives. A degree of inference was required to extract the meaning from the

281 context to reflect natural word learning from reading where explicit definitions are rarely given.

282

283

\section{Design.}

The experiment employed a within-participants and within-items design: participants

were trained on four items through the incidental learning condition and four items through the intentional learning condition. Each participant was trained on only half the total number of stimuli as this was deemed to be a feasible number of new meanings to learn in a single session.

To ensure each new word meaning was seen an even number of times in each condition, and that the order of learning conditions was counterbalanced across participants (to minimise any order effects), we created eight versions of the experiment. Participants were pseudorandomly assigned 
291 to one of the eight versions of the experiment. Time of test (immediate versus 24 hours later) was

292 also within-participants (based on the 31 participants who completed both sessions). The

293 dependent measures were accuracy in cued recall of the new word meanings, and accuracy in the

294 multiple-choice test.

295

296

297

The experiment was run online using Qualtrics (Qualtrics, 2015), and participants were

298 instructed to complete each session in one sitting without breaks. Participants were asked to read

299 the stories and definitions carefully, and were not told that their memory for the new word

300 meanings would be tested. Participants were told that the aim of the experiment was to study

301 subjective reading style and comprehension. After completing the first session, participants were

302 also not informed that they would be contacted at the same time the following day to invite them

303 to complete the second session to discourage the use of deliberate memorisation strategies.

304 Participants read one of the short stories in the incidental learning condition. Each story

305 was divided into five pages of roughly even length and displayed on-screen one page at a time.

306 After each page, a multiple-choice comprehension question appeared on a separate screen asking

307 about details of the story's plot from the preceding page (without probing details of the novel

308 word meanings). Participants were instructed to read the story closely, and to answer a multiple-

309 choice comprehension question after each page. Participants were able to re-read sentences on

310 the current page, although no instructions were given to participants on this; they were not able

311 to go back to reread previous pages. For the comprehension questions participants had to select

312 the correct answer from four options that appeared in a randomised order; they were designed to 
313 be very easy for any participant who had attentively read the text. Participants were excluded if

314 they got more than one of the comprehension questions wrong.

315 The intentional learning condition consisted of two phases which both repeated once:

316 definition sentence reading, followed by two-alternative multiple-choice meaning-to-word

317 matching. In the definition reading phase, participants were presented with sentences that

318 described the key semantic features of each of the novel word meanings, stating the word to

319 which it referred. These four definition sentences were presented one at a time on separate pages,

320 and the order of presentation was randomised for each participant. Participants were instructed to

321 read each definition carefully to make sure they understood it before proceeding to the next one.

322 Once participants had read all of the definition sentences once, they moved immediately

323 on to the two-alternative multiple-choice meaning-to-word matching task. Participants were

324 presented one at a time with three shortened, paraphrased versions of the definitions of each of

325 the novel meanings. For each item participants were instructed to choose the correct word for the

326 new meaning from two options: the correct word and one foil word. After selecting one of the

327 options, participants were provided with feedback, which either said "Correct answer!" or

328 "Incorrect.". The short sentences were presented in a pseudorandomised order, ensuring that the

329 sentences referring to each item were roughly evenly spaced, and none referring to the same item

330 occurred one after another. The foil word for each trial was one of the other words from the

331 intentional training condition. Each foil word was paired an even number of times with each

332 correct word, and the order that the correct word and foil appeared in was randomised for each

333 trial. The two phases of the intentional training were then repeated in the same order. This gave a

334 total of two exposures to the novel word meanings from the definition sentence reading phase

335 and six exposures to the new meanings from the multiple-choice task, totalling eight exposures- 
336 equal to the number of exposures in the incidental learning condition. Participants spent more

337 time reading the story (including comprehension questions; $M=12$ mins $30 \mathrm{secs}, S D=4$ mins

33834 secs) than they spent on the intentional training task ( $M=5$ mins 28 secs, $S D=2$ mins 55

339 secs), $t(39)=11.43, p<.001$.

340 After they had completed training through both the incidental and intentional learning

341 conditions, participants completed a brief filler task. This was the 34-item version of the Mill

342 Hill vocabulary test (Mill Hill Vocabulary Test, Set A: Multiple Choice: Buckner et al., 1996;

343 Raven, Raven, \& Court, 1998). For each item, participants were required to select one word

344 from a list of six options that most closely matched the meaning of the presented word. None of

345 the stimulus items appeared in the filler task. The purpose of this task was to counteract any

346 recency effects of memory for stimulus items encountered toward the end of training; responses

347 were not analysed.

348 Participants were next given a cued recall test of all eight of the new meanings they had

349 encountered in the experiment when presented with the words. Participants saw each of the eight

350 words they had been trained on and were asked to recall the appropriate new meaning and type it

351 into a text box. They were encouraged to provide as much detail as possible and to try to answer

352 in full sentences even if they were unsure of their answer. If they could not remember anything

353 about the new meaning for the word, they were instructed to type "don't know." The order of

354 presentation of the words was randomised for each participant, with the four words from each

355 training method randomly intermixed within the test; this was also the case for the subsequent 356 test.

The second test was an eight-alternative multiple-choice meaning-to-word matching test.

358 Participants were presented one at a time with paraphrased definitions of the novel word 
359 meanings they had been trained on. The sentences omitted the words to which they were

360 referring, and for each novel meaning participants were asked to select the word that they

361 thought matched the definition from a list of all eight of the stimulus words they had encountered

362 throughout the experiment. The order of the eight words to choose from was randomised for each

363 test item, and the order of presentation of the new meanings was randomised for each participant.

364 Finally, participants provided their demographics details and answered some questions

365 about their reading habits. These questions were used to maintain the impression that the

366 experiment was investigating general reading and comprehension and the responses were not

367 analysed.

368 Exactly 24 hours after the first session, participants were invited to take part in a short

369 24-hour follow-up to the experiment. Thirty-one participants completed the follow-up tests,

370 which they did an average of 24 hours and 1 minute $(S D=54$ minutes, range $=22 \mathrm{~h} 26 \mathrm{~m}-28 \mathrm{~h} 2 \mathrm{~m})$

371 after the first session. The follow-up tests consisted of a repeat of the two tests from the first

372 session of the experiment in the same order.

373

374 Results

$375 \quad$ Analysis procedure.

376 Responses from the multiple-choice test were either coded as "1" for correct or " 0 " for

377 incorrect with regards to which word had been selected to match with the meaning. Responses

378 for the cued recall test were independently coded for accuracy by the experimenter and a

379 research assistant, blind to condition, as either "1" for correctly recalled meanings or " 0 " for 
380 incorrect $^{1}$. Responses were leniently coded as correct if at least one correct semantic feature was

381 recalled. Any ambiguous or partially correct responses were resolved on a case-by-case basis

382 through discussion. One item ("bruise") was excluded from the analyses for the cued recall

383 measure, as the percentage of participants who gave a correct response for that item in one of the

384 two learning conditions (incidental, 20.0\%) was more than two standard deviations below the

385 grand mean for all items across both learning conditions $(M=72.3 \% ; S D=23.5)$.

386

Data were analysed with logistic mixed effects models using the lme4 package

387 (version1.1-7; Bates et al., 2015) and R statistical software (version 3.0.2; R Core Team, 2017).

388 Four separate models were created: one for each test measure comparing the accuracy between

389 day one and day two (including only the participants who completed both test sessions, $N=31$ ),

390 and for each measure for all participants tested on day one only $(N=40)$. These latter analyses

391 aimed to verify that the data from this larger set of participants did not differ from the subset who

392 chose to complete both sessions.

393 Due to a potential effect of counterbalancing order, in that participants who completed

394 the intentional condition first may suspect that they would be tested on the words in the stories,

395 we included a factor for the order of the learning conditions in our models. The contrasts for the

396 fixed effects were defined using deviation coding for learning condition (incidental: -0.5 ,

397 intentional: 0.5 ), and the order of the learning conditions (first: -0.5 , second: 0.5 ), with the

398 interaction coded by multiplying the contrasts for these two factors. The two models comparing

399 performance between day one and day two contained additional fixed effects for time (day one: -

400 0.5, day two: 0.5 ), and the interactions between time and learning condition, time and learning

\footnotetext{
${ }^{1}$ While each new meaning comprised three distinguishing semantic features, due to the natural integration of the new word meanings into the stories not all of the semantic features were mentioned at each occurrence. Because it was more difficult to control even exposure to all of the semantic features in the incidental condition (stories), we were concerned that a scaled accuracy measure of the number of semantic features recalled would be biased towards the intentional condition. We therefore decided to score recall responses with a binary accuracy score.
} 
401 order, and the three-way interaction. Random effects structures were determined by identifying

402 the maximal model (Barr et al., 2013). This included by-participant and by-item random

403 intercepts, and by-participant and by-item random slopes for learning condition ${ }^{2}$. The models

404 comparing performance between day 1 and day 2 also included by-participant and by-item

405 random slopes for time and the interaction between time and learning condition. Where the

406 maximal model failed to converge, we simplified the models by removing the correlations

407 between the by-participant and by-item random slopes and random intercepts without removing

408 any of the random slopes, as recommended by Barr et al. (2013). Significance of the fixed effects

409 and interactions was assessed using likelihood ratio tests comparing the full model to models

410 with each fixed factor/interaction of interest removed in turn (but leaving in any interaction

411 involving a factor of interest that has been removed). Follow-up analyses were carried out in the

412 case of any significant interaction using the same method. The p-values for the simple effects

413 analyses were compared against a Bonferroni-corrected $\alpha$ of .025 . All data and analysis scripts

414 for this experiment are available via the Open Science Framework (OSF; https://osf.io/k32tw).

415

416

\footnotetext{
${ }^{2}$ Random slopes for the controlled factor of learning order were not included due to issues of model nonconvergence. This factor was not of theoretical interest and the fixed effect for this factor was not significant in any
} of the models.

Peer] reviewing PDF | (2020:11:55152:1:0:NEW 23 May 2021) 
422 The LME analyses were carried out on the raw binary accuracy data, however mean percentage

423 accuracy data are displayed in the graphs for ease of interpretation. Error bars show standard

424 errors for the means, adjusted for the within-participant design (Cousineau, 2005).

425

426

427

430

431

432

434

436

437

438

439

440

441

442

443

444

The accuracy data for cued recall of the new meanings comparing performance between day one and day two $(N=31$; see Figure 1$)$ showed a reasonably high level of accuracy for items learned through both learning conditions. But accuracy was significantly higher overall for items learned through the intentional learning condition (day one: $85.2 \%$; day two: $84.9 \%$ ) than those learned under incidental conditions (day one: 62.1\%; day two: 70.1\%) $\left[\chi^{2}(1)=14.32, p<.001\right]$. There was no significant main effect of time of test $\left[\chi^{2}(1)=1.23, p=.268\right]$, nor of learning order $\left[\chi^{2}(1)=0.83, p=.362\right]$. While accuracy improved slightly between day one and day two for items learned through the stories and remained at a similar level for items learned through the intentional condition, the interaction between learning condition and time was non-significant $\left[\chi^{2}(1)=1.57, p=.210\right]$. The interactions between learning condition and learning order $\left[\chi^{2}(1)=\right.$ $2.16, p=.141]$, learning order and time of test $\left[\chi^{2}(1)=1.79, p=.181\right]$, and the three-way interaction $\left[\chi^{2}(1)=0.83, p=.361\right]$ were also non-significant.

The accuracy data for all participants on day one only $(N=40)$ showed a similar pattern: significantly higher accuracy for items learned through the intentional training condition than the incidental condition $\left[\chi^{2}(1)=21.35, p<.001\right]$, and no significant main effect of learning order $\left[\chi^{2}(1)=0.0007, p=.979\right]$. However, there was a significant interaction between learning condition and learning order $\left[\chi^{2}(1)=4.68, p=.030\right]$ : accuracy was higher for items learned through the stories when this had been the first condition in the experiment $(70.0 \%)$ than when this had been the second condition (47.5\%), whilst the opposite was the case for items learned 
445 through the intentional condition (first: 82.1\%; second: 95.0\%). This unexpected result could

446 have been driven by participants becoming somewhat fatigued by the second task and this

447 fatigue effect having greater impact on the story reading task, which took longer. However, this

448 does not perhaps explain why participants performance in the intentional condition was slightly

449 higher when it was the second condition in the experiment rather than the first condition.

450

452

453

454

455

456

457

459

460

461

462

463

464

465

466

467

\section{Multiple-choice meaning-to-word matching.}

\section{[Figure 2.png]}

Figure 2. Experiment 1. Mean percentage of correct responses on the multiple-choice test for each learning condition, when tested on day one (immediately after learning) and day two (24 hours later; $N=31)$.

Error bars show standard errors for the means, adjusted for the within-participant factor of learning condition (Cousineau, 2005).

The results for accuracy on the multiple-choice meaning-to-word matching test comparing results between day one and day two $(N=31)$ are shown in Figure 2. Accuracy was high in both learning conditions, but was slightly higher for the intentional learning condition (day one: $96.0 \%$; day two: $87.9 \%$ ) than for the incidental learning condition (day one: $83.9 \%$; day two: $83.1 \%$, although this difference was non-significant $\left[\chi^{2}(1)=3.66, p=.056\right]$. The main effect of time was also non-significant $\left[\chi^{2}(1)=3.81, p=.051\right]$, as was the main effect of learning $\operatorname{order}\left[\chi^{2}(1)=0.002, p=.966\right]$. Interestingly, the interaction between learning condition and time was significant $\left[\chi^{2}(1)=3.85, p=.05\right]$. The interaction between learning condition and learning 
468 order was non-significant $\left[\chi^{2}(1)=2.24, p=.135\right]$, as was the interaction between time and

469 learning order $\left[\chi^{2}(1)=0.01, p=.929\right]$, and the three-way interaction $\left[\chi^{2}(1)=0.48, p=.488\right]$.

470 To follow up on the significant interaction between learning condition and time, two

471 simple effects analyses were carried out to determine the significance of time within each of the

472 two learning conditions separately. For the incidental learning condition there was no significant

473 effect of time $\left[\chi^{2}(1)=0.10, p=.750\right]$, indicating no forgetting between day one and day two.

474 However, there was a significant effect of time for the intentional learning condition $\left[\chi^{2}(1)=\right.$

$4756.07, p=.014]$, which was slightly lower on day two than day one. (The $\mathrm{p}$-values for these

476 simple effects analyses were compared against a Bonferroni-corrected $\alpha$ of .025.)

477

In the accuracy data for the multiple-choice test for all participants on day one only $(N=$

478 40), accuracy was again high overall for both conditions. Accuracy appeared slightly higher for

479 items learned through the intentional condition (95.7\%) than for items learned through the

480 incidental condition $(81.9 \%)$, but there was no significant main effect of learning condition $\left[\chi^{2}(1)\right.$

$481=1.18, p=.277]$. There was also no significant main effect of learning order $\left[\chi^{2}(1)=0.004, p=\right.$

$482.950]$, and no significant interaction $\left[\chi^{2}(1)=2.52, p=.113\right]$.

483

484 Discussion

485 Experiment 1 aimed to determine how easily novel meanings for familiar words can be

486 acquired incidentally through story reading, as compared with a more intentional learning

487 procedure. The results showed that accuracy in cued recall of new word meanings was

488 significantly higher in the intentional learning condition than the incidental learning condition:

$48985.2 \%$ compared with $62.1 \%$ when measured immediately after training. The accuracy data for

490 the multiple-choice meaning-to-word matching test showed a similar pattern $(96.0 \%$ for the 
491 intentional condition and $83.9 \%$ for the incidental condition at the immediate test), although for

492 this measure the main effect of learning condition was non-significant. Furthermore, reading the

493 story took participants a significantly longer amount of time, so more was learned in a shorter

494 amount of time through the intentional training task.

495 These findings are broadly consistent with those of L2 vocabulary learning studies that

496 have found intentional learning to be more efficient than incidental learning of vocabulary

497 (Hulstijn, 1992; Peters et al., 2009). Although recall accuracy was higher for the intentional

498 learning condition, there was also a reasonably high level of acquisition of new meanings for

499 familiar words through the incidental learning condition. This is very similar to the results of the

500 study by Hulme et al. (2019), where accuracy in recalling new meanings for familiar words was

$50163.5 \%$ after eight exposures in an incidental learning context (accuracy in cued recall of word

502 forms was $69.2 \%$ ). These results therefore support the findings of recent studies showing good

503 acquisition of L1 vocabulary from reading (Batterink \& Neville, 2011; Godfroid et al., 2017;

504 Pellicer-Sánchez, 2016). An additional consideration is that we included multiple-choice

505 comprehension questions between pages of the stories in our incidental learning condition. While

506 these did not probe details of the new word meanings, it is possible that they could have

507 improved comprehension by increasing metacognitive awareness of the comprehension process,

508 similar to a "guided learning" scenario (Blything et al., 2020).

Interestingly, the multiple-choice test showed a significant interaction between learning

510 condition and time of test, although there was no such significant interaction in the recall

511 measure. Following up on the significant interaction in the multiple-choice measure, simple

512 effects analyses showed that there was significant forgetting after 24 hours of items learned in

513 the intentional condition ( $8 \%$ reduction in accuracy between the immediate test and delayed test), 
514 but there was no forgetting of items learned incidentally through story reading. This absence of

515 significant forgetting after a 24-hour delay replicates the finding from Hulme et al. (2019) who

516 reported no significant forgetting on this paradigm after a seven-day delay. A possible

517 explanation for this lack of forgetting is that new word meanings learned in a more semantically

518 rich context, such as from stories, may be retained better. New word meanings encountered in

519 stories will contain additional contextual information relating to the narrative (e.g., characters'

520 thoughts and feelings), providing additional cues for participants to rely on for later retrieval.

521 The stories are also more interesting and engaging so may be more memorable for participants in

522 general. However, another possibility is that this difference is a function of initial learning level,

523 as initial performance was very high in the intentional condition and so had further to fall. A

524 further alternative explanation for this finding is that the lack of forgetting of items learned

525 incidentally through story reading could be due to memory reactivations during sleep. Memory

526 consolidation during sleep has been shown to be preferential towards initially weaker memory

527 traces and less supportive to memories that have already established robust representations

528 (Drosopoulos et al., 2007). Since recall and recognition accuracy was lower for items acquired

529 through incidental learning conditions, this is a compelling alternative explanation for why there

530 was less forgetting of items learned through story reading.

531 In addition, the additional retrieval practice for the test immediately after training may

532 have aided learning in the incidental, story reading condition. Further supporting this possibility,

533 items learned through the incidental condition showed a slight improvement ( $8 \%$ increase) in

534 cued recall accuracy between the test on day one and the test on day two. The second test task in

535 the immediate test session (multiple-choice meaning-to-word matching) may therefore have

536 boosted learning, manifesting as improved cued recall at the delayed test. The potential 
537 involvement of a testing effect (Roediger \& Karpicke, 2006a) in long-term retention of new

538 meanings for familiar words will be examined in detail in Experiment 2 and Experiment 3.

\section{Experiment 2: The testing effect in incidental and intentional learning}

meanings that were learned through story reading can be boosted by introducing a test of participants' knowledge immediately after training. As with Experiment 1, performance will be compared to a more conventional explicit learning baseline (the same intentional training procedure as in Experiment 1). Participants were tested immediately after training on half of the items they saw in each learning condition, and then given a surprise test 24 hours later in which they were tested on the other half of the items for the first time, as well as being retested on items that had been tested the previous day. As for Experiment 1, both test sessions consisted of cued recall of the new meanings, followed by a multiple-choice meaning-to-word matching test. immediately after training, compared with those that were not tested, for both the incidental and intentional conditions. There was no specific prediction as to whether the magnitude of the testing effect would differ for the different learning conditions. Additionally, we expected to replicate the findings from Experiment 1 that retention would be better overall for novel meanings learned through intentional conditions, but that there would be less forgetting under incidental conditions. can be retrieved from https://osf.io/e5zmk (Hulme \& Rodd, 2016, November 4). Any deviations

559 from the preregistration are noted in the Method and Results sections for this experiment. The 
560 materials, data, and analysis scripts for Experiment 2 can be found on the Open Science

561 Framework (OSF; https://osf.io/upmnr).

562

563 Method

564

Participants.

565

We aimed to recruit 96 participants for Experiment 2 in which participants were trained 566 on eight items (two items per cell: four per learning condition, and four per test type) in one of 16 experiment versions (six participants per version). The sample size was established in consideration of the study by Hulme et al. (2019) and Experiment 1 . As this experiment has the additional independent variable of test type, a larger sample size was used in Experiment 2 than Experiment 1 to achieve comparable power with a smaller number of items per cell. Ninety-nine participants were included in the experiment (age: $M=32.31$ years, $S D=$ 8.14; 56 female); we accidentally over-recruited by three participants when pseudorandomly assigning participants to the experiment versions and kept these participants. Participants were recruited in the same way as for Experiment 1 . They gave their informed consent before taking part (by means of ticking boxes in the online consent form) and were paid for their participation at the end of each session ( $£ 6$ for session one and $£ 2$ for session two). The UCL Experimental Psychology Ethics Committee granted ethical approval for the research (Ref: EP/2017/009). An additional 36 participants took part in the first session but did not complete session two by the deadline (within six hours of receiving the invitation for the delayed test) and were excluded. (This additional data exclusion was used for Experiments 2 and 3 to ensure sufficient power to examine the testing effect within-participants, for which a complete set of immediate and delayed test data was critical.) A further twenty-one participants were excluded due to 
583 getting more than one of the multiple-choice comprehension questions wrong when reading the

584 stories (see Experiment 1 Procedure), and two further participants were excluded for attempting

585 the experiment more than once. Finally, five participants were excluded for being outliers in their

586 mean reading speed (faster than 543.4 words per minute, $2 S D$ above the mean). Excluded

587 participants were replaced during recruitment.

588

589

\section{Materials.}

The stimuli for the present experiment were identical to those used in Experiment 1.

591

592

\section{Design.}

593

The experiment used a within-participants and within-items design, with two independent

594 variables: learning condition (two levels: incidental and intentional) and test type (three levels:

595 immediate test (tested in the first session), delayed test (tested for the first time in the second

596 session), and delayed retest (tested for the second time in the second session)). The dependent

597 variables were accuracy in cued recall of meanings and multiple-choice meaning-to-word

598 matching.

599 There were sixteen versions of the experiment to ensure the items were seen an even

600 number of times in each condition, with the order of the learning conditions counterbalanced

601 across participants. Participants were pseudorandomly assigned to one of the sixteen versions of

602 the experiment. As in Experiment 1, each participant was trained on half the total number of

603 stimuli (eight items; four in each learning condition), with the items in each condition and the

604 order of the learning conditions counterbalanced across participants. Further counterbalancing 
605 accounted for which stimulus items were or were not tested immediately following training 606 across participants.

607

$608 \quad$ Procedure.

609 The procedure for the incidental and intentional learning conditions was identical to that

610 of Experiment 1, and immediately following training participants completed the same Mill Hill

611 vocabulary test (Mill Hill Vocabulary Test, Set A: Multiple Choice: Buckner et al., 1996; Raven

612 et al., 1998) as a filler task. Participants were then immediately tested on half of the items that

613 they had been trained on through the incidental and intentional learning conditions (four items,

614 two trained through each training method). The tests were the same as for Experiment 1: cued

615 recall of meanings followed by multiple-choice meaning-to-word matching. The items were

616 tested in a random order in each of the two tests, with no feedback given to participants. In the

617 multiple-choice test only the four words that a participant was being immediately tested on

618 appeared as the four alternative responses to choose from for each test item; the order of these

619 was also randomised for each test item.

620 Exactly 24 hours after the first session of the experiment had been made available,

621 participants were asked to take part in the second session: the delayed test. Participants were not

622 aware beforehand that they would be asked to complete this test to discourage them from

623 rehearsing and intentionally retaining information about the novel word meanings. As such,

624 unfortunately 36 participants did not return to complete session two; 99 participants were

625 therefore included in the analysis. Participants began the delayed test an average of 24 hours and

62625 minutes $(S D=57 \mathrm{mins}$, range $=22 \mathrm{~h} 45 \mathrm{~m}-27 \mathrm{~h} 21 \mathrm{~m})$ after the training session. The tests were

627 the same as those that had been used for the immediate test in the same order. This time 
628 participants were tested on all of the stimuli that they had been trained on (eight items). The

629 order of presentation of the items in each of the two tests was again randomised for each

630 participant, and for the multiple-choice test the order of the eight stimulus words to choose from

631 was again randomised for each test item.

632

633 Results

634

Analysis procedure.

635

Responses for the cued recall test and multiple-choice test were coded for accuracy ("1"

for correct and " 0 " for incorrect) in the same way as for Experiment 1.

637

Upon completion of the experiment, we realised that test type was confounded with

638

differing test difficulty between the immediate test and the two delayed test types for the

639

multiple-choice meaning-to-word matching measure. This was because in the immediate test

640

participants could choose from four alternative words to pair with the appropriate meaning on

641

each trial (as they were only tested on half the total items they were trained on: four items, two

642

trained through each training condition). In contrast, in the delayed test participants had to

643

choose from eight alternatives (as they were tested on all eight of the items they had been trained

on). The results from the immediate multiple-choice test are therefore not comparable to the

645

results from the two delayed test types, so the analysis for this measure was only carried out on

646

the subset of results for the two delayed test types. This is a deviation from the analysis plan

647

outlined in the preregistration of this experiment. The analysis of the cued recall measure was

648

carried out according to the preregistration.

649

The data were analysed, as in the previous experiment, using logistic mixed effects

650

models with the lme4 package (version 1.1-12; Bates et al., 2015) and R statistical software

Peer] reviewing PDF | (2020:11:55152:1:0:NEW 23 May 2021) 
651 (version 3.3.2, R Core Team, 2017), with two separate models for the analysis of data from the

652 two measures. The model used to analyse the cued recall data contained three factors: test type

653 (three levels: immediate, delayed first test, delayed second test), learning condition (two levels:

654 incidental, intentional), and order of the learning conditions in the experiment (two levels: first,

655 second). The contrasts for the fixed effect of test type were defined using Helmert coding, with

656 one contrast comparing the immediate test to the two delayed tests combined (immediate: 0.67 ,

657 delayed first test: -0.33 , delayed second test: -0.33 ), and a second comparing the two delayed test

658 types to each other (immediate: 0 , delayed first test: -0.5 , delayed second test: 0.5 ). Deviation

659 coding was used to specify the contrasts for the fixed effects of learning condition (incidental: -

660 0.5, intentional: 0.5 ) and learning order (first: -0.5 , second: 0.5 ).

661 The model used to analyse the multiple-choice data also had three factors: test type (2

662 levels: delayed first test, delayed second test), learning condition (2 levels: incidental,

663 intentional), and learning order (2 levels: first, second). The contrasts were specified using

664 deviation coding for the fixed effects of test type (delayed first test: -0.5 , delayed second test:

665 0.5), learning condition (incidental: -0.5 , intentional: 0.5), and learning order (first: -0.5 , second:

666 0.5). The procedure for determining the appropriate random effects structure and significance of

667 the fixed effects/interactions was the same as described for Experiment 1. The model used to

668 analyse the multiple-choice data used the maximal random effects structure; the one for the cued

669 recall measure was simplified by removing the correlations between the by-participant and by-

670 item random slopes and random intercepts (as recommended by Barr et al., 2013).

671 Following on from the main analysis for the cued recall measure, firstly three pairwise

672 comparisons (with Bonferroni adjustment for multiple comparisons, $\alpha=.017$ ) were carried out to

673 compare the different levels of test type to each other. This was done by taking a subset of the 
674 data for each pair of levels of test type and creating a model for each containing the same fixed

675 and random effects as the model used for the main analysis, although the contrast for test type

676 was coded using deviation coding (immediate: 0.5 , delayed first test: -0.5 ; immediate: 0.5 ,

677 delayed second test: -0.5 ; delayed first test: -0.5 , delayed second test: 0.5 ). Secondly, further

678 follow-up pairwise comparisons (with Bonferroni correction for multiple comparisons, $\alpha=.017$ )

679 were made for the three $2 \times 2$ interactions between the pairs of test types and the two learning

680 conditions to determine whether the difference between any two test types differed between the

681 two learning conditions. Finally, six simple effects pairwise comparisons (with Bonferroni

682 adjustment for multiple comparisons, $\alpha=.008$ ) were run to test for any significant differences

683 between the different test types within the two learning conditions. This was done by taking

684 further subsets of the data for the pairs of levels of test type separately for the incidental and

685 intentional learning conditions and creating models with only fixed effects for test type, learning

686 order, and the interaction (with random effects for test type for participants and items).

687 The only follow-up analyses carried out for the multiple-choice test were two simple

688 effects pairwise comparisons (with Bonferroni correction for multiple comparisons, $\alpha=.025$ ).

689 This was done in the same way as the simple effects analyses for the cued recall measure. All

690 data and analysis scripts for this experiment are available via the Open Science Framework

691 (OSF; https://osf.io/upmnr).

692

$693 \quad$ Cued recall of meanings.

694 Data for the cued recall test (Figure 3) showed that accuracy was significantly higher for

695 items trained through the intentional than the incidental learning condition $\left[\chi^{2}(1)=34.83, p<\right.$

$696.001]$. There was also a significant main effect of test type $\left[\chi^{2}(2)=25.78, p<.001\right]$; the main 
697 effect of learning order was non-significant $\left[\chi^{2}(1)=2.50, p=.114\right]$. There was a significant

698 interaction between learning condition and test type $\left[\chi^{2}(2)=13.86, p<.001\right]$, but the interaction

699 between learning condition and learning order was not significant $\left[\chi^{2}(1)=0.09, p=.760\right]$. There

700 was an unexpected significant interaction between test type and learning order $\left[\chi^{2}(2)=9.24, p=\right.$

$701.010]$; the three-way interaction was not significant $\left[\chi^{2}(2)=3.23, p=.199\right]$. (Results for all the

702 analyses for the cued recall test are also presented in Table 1 for clarity of the different levels of 703 follow-up analysis for this measure.)

[Figure 3.png]

Figure 3. Experiment 2. Mean percentage of correct responses in the cued recall test for each learning condition and for the three different test types in the experiment.

Error bars show standard error of the means adjusted for the within-participant design

709 (Cousineau, 2005).

710

711

[Table 1.docx]

712

Table 1. Results for the linear mixed effects model analyses for the cued recall test in

results reported are for likelihood ratio tests comparing the full model to models with each fixed factor/interaction of interest removed in turn. significant effect of overnight forgetting (difference between the delayed $1^{\text {st }}$ and immediate tests) 
$720\left[\chi^{2}(1)=19.99, p<.001\right]$, with better recall of new meanings when tested immediately than when

721 tested for the first time after a delay. There was also a significant testing effect (difference

722 between the delayed $2^{\text {nd }}$ and delayed $1^{\text {st }}$ tests) $\left[\chi^{2}(1)=18.83, p<.001\right]$, with higher recall

723 accuracy for items that were being tested for the second time than for those being tested for the

724 first time after the delay. However, there was no significant difference in cued recall accuracy

725 between the immediate and delayed $2^{\text {nd }}$ tests $\left[\chi^{2}(1)=0.89, p=.345 ; \alpha=.017\right]$, suggesting these

726 items were protected against forgetting.

727 To further investigate the significant interaction between learning condition and test type,

728 the second set of follow-up analyses were pairwise comparisons for the three $2 \times 2$ interactions

729 between the pairs of test types and the two learning conditions. Results showed that there was a

730 significant interaction between learning condition and the difference between the immediate and 731 delayed $2^{\text {nd }}$ tests $\left[\chi^{2}(1)=16.24, p<.001\right]$. Items learned incidentally from stories showed some

732 improvement between the immediate test and the retest on day two, while items learned through

733 the intentional learning condition showed a small amount of forgetting. There was no significant

734 interaction between learning condition and the difference between either the immediate and

735 delayed $1^{\text {st }}$ tests $\left[\chi^{2}(1)=2.29, p=.130\right]$ or between the delayed $1^{\text {st }}$ and delayed $2^{\text {nd }}$ tests $\left[\chi^{2}(1)=\right.$

$7362.97, p=.085 ; \alpha=.017]$.

737 In the final set of follow-up analyses, six simple effects pairwise comparisons were run to

738 test for any significant differences between the different test types within the two learning

739 conditions. The results revealed that for the incidental learning condition there was no significant

740 difference in recall accuracy for items tested for the first time after the delay than for items tested

741 immediately after training at the corrected level $\left[\chi^{2}(1)=5.88, p=.015\right]$, that is no significant

742 forgetting. There was significantly better cued recall accuracy for items tested for the second 
743 time after the delay than those tested for the first time $\left[\chi^{2}(1)=15.27, p<.001\right]$ : a significant

744 testing effect. There was also significantly better recall of new meanings tested for the second

745 time after the delay than the immediate test $\left[\chi^{2}(1)=14.59, p<.001\right]$. For the intentional learning

746 condition, there was significantly lower recall accuracy for items tested for the first time after the

747 delay than those tested immediately $\left[\chi^{2}(1)=18.27, p<.001\right]$, showing significant forgetting.

748 There was better recall accuracy for items tested for the second time after the delay than those

749 tested for the first time $\left[\chi^{2}(1)=8.39, p=.004\right]$ : a significant testing effect. There was no

750 significant difference (at the corrected level) between items tested for the second time following

751 the delay and when tested immediately after training $\left[\chi^{2}(1)=4.25, p=.039 ; \alpha=.008\right]$.

752

Additionally, although not specified in the preregistration, exploratory follow-up analyses

753 were carried out to examine the nature of the unexpected interaction between test type and

754 learning order. These were three pairwise comparisons of the $2 \times 2$ interactions between the pairs

755 of test types and the two learning orders (first or second position in the experiment). Results

756 revealed a significant interaction between position and the difference between the delayed $1^{\text {st }}$ and

757 delayed $2^{\text {nd }}$ tests $\left[\chi^{2}(1)=7.12, p=.008\right]$. Items appeared to be recalled better at the delayed $1^{\text {st }}$

758 test when they had been presented in the first condition in the training session, whereas items

759 were recalled better at the delayed $2^{\text {nd }}$ test when they had been trained in the second condition.

760 There was no significant interaction between the immediate and delayed $2^{\text {nd }}$ tests $\left[\chi^{2}(1)=0.12, p\right.$

$761=.729]$, nor between the immediate and delayed $1^{\text {st }}$ tests $\left[\chi^{2}(1)=5.15, p=.023\right]$ at the

762 Bonferroni-corrected level $(\alpha=.017)$. However, further follow-up analyses of the simple effects

763 pairwise comparisons of learning order within the delayed $1^{\text {st }}$ and delayed $2^{\text {nd }}$ test types were

764 both non-significant at the Bonferroni-corrected level (both $p>.025$ ). 


\section{Multiple-choice meaning-to-word matching.}

767

The analysis of the data for the multiple-choice meaning-to-word matching test (Figure 4)

768

769

770

771

772

773

774

775

776

777

778

779

780

781

782

783

784

785

786

787

788

777

\section{4}

was only carried out on the subset of results for the two delayed test types. Overall accuracy was

very high, and it was significantly higher for items trained intentionally than incidentally across all test types $\left[\chi^{2}(1)=8.44, p=.004\right]$. The main effect of test type was also significant $\left[\chi^{2}(1)=\right.$

$6.71, p=.010]$, with slightly greater accuracy for items that had been tested previously than for those that had not been; there was no significant main effect of learning order $\left[\chi^{2}(1)=0.32, p=\right.$ .569]. The interaction between learning condition and test type was not significant $\left[\chi^{2}(1)=0.61\right.$, $p=.435]$, nor was the interaction between learning condition and learning order $\left[\chi^{2}(1)=1.23, p\right.$ $=.268]$, nor the interaction between test type and learning order $\left[\chi^{2}(1)=1.32, p=.251\right]$. The three-way interaction was also not significant $\left[\chi^{2}(1)=0.06, p=.810\right]$.

\section{Figure 4. Experiment 2. Mean percentage of correct responses in the multiple-choice test}

\section{[Figure 4.png]}

\section{for each learning condition and for the three different test types in the experiment.}

Note that the results from the immediate test (with lighter shading) are not comparable to those

from the two delayed test types due to an underlying difference in test difficulty. Error bars show standard error of the means adjusted for the within-participant design (Cousineau, 2005).

Following on from the main analysis, two simple effects pairwise comparisons tested for any significant differences between the different test types within the two learning conditions. In the incidental learning condition, the difference between items tested for the second time following the delay and those tested for the first time was non-significant at the corrected level 
$789\left[\chi^{2}(1)=4.62, p=.032\right]$. For the intentional learning condition, there was also no significant

790 difference in accuracy between items tested for the first or second time after the delay $\left[\chi^{2}(1)=\right.$

$7913.53, p=.060 ; \alpha=.025]$.

792

793 Discussion

794

The aim of Experiment 2 was to examine whether testing memory immediately after

training enhances long-term retention of new word meanings acquired through incidental and

796

intentional learning conditions, and to see whether any testing effect differs depending on the

797

learning conditions. As in Experiment 1, new word meanings were learned better overall through

798

intentional learning conditions than through incidental learning conditions. Accuracy in both the

799

cued recall and multiple-choice tests was significantly higher for items trained through the

800

intentional learning condition

801

Cued recall accuracy was also higher overall immediately after training than when items

802

were tested for the first time after 24 hours. This demonstrates some overnight forgetting of the

803

new meanings for the words in the absence of an intervening test. Furthermore, there was

804

numerically but not significantly (at the corrected level) more forgetting of items trained through

805

the intentional learning condition than those learned through a story, both with and without prior

806 retrieval practice. This is in line with the findings of Experiment 1, where accuracy on the

807 multiple-choice test was lower after 24 hours for items learned through the intentional condition,

808 but not for items learned through the stories.

809 Critically, both the cued recall and multiple-choice tests revealed an overall testing effect:

810 new word meanings were recalled and recognised significantly better after 24 hours when they

811 had been tested immediately after training than when they were being tested for the first time. As 
812 predicted, in the cued recall measure this main effect of testing was also significant in the simple

813 effects analyses that looked at incidental and intentional learning separately. This is in line with

814 studies that have found a benefit of prior retrieval on learning information from different

815 contexts, such as list of foreign language vocabulary words and their translations (van den Broek

816 et al., 2013) and information from prose passages (Roediger \& Karpicke, 2006b).

817 The lack of difference in cued recall accuracy between performance on the immediate

818 test and the delayed test for items being tested for the second time suggests that the retrieval

819 practice protected these items against forgetting. The testing effect seen in the present study

820 therefore at least partly explains why participants in Experiment 1 and those in the study by

821 Hulme et al. (2019) showed such good retention after one day and one week respectively. In the

822 present experiment both the cued recall and multiple-choice tests were administered to all

823 participants at both time points. It is therefore unclear whether either of these tests on its own

824 would produce a similar testing effect, or if the combination of the two was important for

825 boosting long-term retention. It also remains to be seen whether one of these test types is better

826 than the other for enhancing retention of new word meanings learned incidentally through

827 reading.

828 In sum, Experiment 2 demonstrated that testing memory of new meanings for familiar

829 words benefits their future retention. This was the case for recalling word meanings learned

830 either incidentally through story reading or through an intentional learning condition. As in

831 Experiment 1, participants learned vocabulary more efficiently through the intentional learning

832 condition, but performance for both learning conditions was good. There was a trend in the data

833 towards less forgetting of items trained incidentally through the stories, and a trend suggesting a

834 larger testing effect for incidentally-trained items. However, these interactions were non- 
835 significant; further research is warranted to investigate whether incidentally-trained items in

836 particular could benefit from the additional learning opportunity afforded by the immediate test.

837 Either the immediate cued recall or multiple-choice test, or indeed a combination of the two, may

838 have produced the observed testing effect; Experiment 3 will investigate which of these test

839 methods could be more beneficial for retention. The results of this experiment will guide future

840 development of real-world intervention studies aimed to boost vocabulary learning from story

841 reading.

842

\section{Experiment 3: Immediate test method}

844

The testing effect has been observed in studies using various methods of immediate test,

845 most usually with cued recall (e.g., Karpicke \& Smith, 2012), but also with other methods such

846 as multiple-choice (e.g., Roediger \& Marsh, 2005). There are several possibilities as to why

847 certain methods of immediate testing may be more beneficial for future retention. The retrieval

848 effort hypothesis states that testing is more helpful for long-term retention when it is more

849 effortful (Pyc \& Rawson, 2009). For example, in a study in which young adults learned the

850 meanings of novel L1 vocabulary words, Karpicke and Roediger (2007) showed that increasing

851 retrieval difficulty by increasing the delay between initial study and initial testing led to better

852 long-term retention than when initial retrieval effort was lower. Tests of productive vocabulary

853 knowledge, such as cued recall of word meanings, are more difficult than recognition tests in

854 which word meanings are supplied (Pellicer-Sánchez, 2016); therefore an immediate cued recall

855 test may be more advantageous for future retention than a multiple-choice test. Indeed, findings

856 from many studies (for a review see Rowland, 2014) suggest effortful processing to be an

857 important attribute of the testing effect. 

restructuring learned information into a format that is more helpful for long-term retention.

860 Multiple-choice recognition tests may aid retention due to response choices cueing the retrieval 861 of marginal knowledge that may otherwise not be easily accessible (Marsh et al., 2007). They

862 may also provide an opportunity for additional learning of some items through the process of

863 elimination of foils (Marsh et al., 2007) even in the absence of feedback on response choice.

864 However, foil answers in multiple-choice tests may also lead to learning of incorrect information 865 (Butler et al., 2006; Marsh et al., 2007; Roediger \& Marsh, 2005).

866 Some studies have directly compared the effects of immediate cued recall and multiple867 choice tests on long-term retention. Duchastel (1981) investigated secondary school students’

868 retention of a prose passage following immediate testing with either a short-answer test (akin to 869 cued recall), a multiple-choice test, or a free recall test. Long-term retention (measured by a 870 delayed cued recall test) was better for those who had the immediate short-answer test, but no 871 testing effect was observed for the other two groups. However, Duchastel (1981) found no 872 testing effect for any group on the delayed free recall test, and the delayed cued recall measure 873 was very similar to the immediate test for the short-answer test group. More recently, Nakata 874 (2016) compared retrieval methods including cued recall and multiple-choice recognition in a 875 study of paired-associate learning of novel L2 words. Recall was found to be most beneficial for 876 acquiring novel words' orthography (spelling), whereas recognition was more beneficial 877 otherwise (Nakata, 2016).

878 One concern is that information learned with the help of retrieval practice could be 879 relatively inflexible and constrained, and may therefore not transfer to different delayed tests. 880 Tran et al. (2014) and others have found that retrieval practice may not benefit later tests that 
881 require making deductive inferences about the learned information. Furthermore, Hogan and

882 Kintsch (1971) found that immediate test methods that provide further exposure (i.e., recognition

883 tests) were more beneficial than free recall for recognition two days later, whereas both free

884 recall and recognition boosted performance on delayed free recall.

885 However, the degree to which different methods of immediate test aid future retention

886 can also differ depending on factors such as the provision of feedback. Kang et al. (2007) found

887 that participants who had an immediate multiple-choice test performed better on delayed

888 multiple-choice and short-answer tests than participants who had an immediate short-answer test

889 (Experiment 1; Kang et al., 2007). However, in a second experiment where feedback was

890 provided on initial test performance (Experiment 2; Kang et al., 2007), the group with the

891 immediate short-answer test performed better on the delayed tests than those whose immediate

892 test had been multiple-choice, supporting the retrieval effort hypothesis (Pyc \& Rawson, 2009).

893 Other studies have also found that the testing effect can transfer across different test methods

894 (Butler, 2010; McDaniel, Anderson, et al., 2007; Rohrer et al., 2010), with cued recall usually

895 found to be more beneficial for long-term retention than recognition tests.

896 The aim of Experiment 3 was to investigate the impact of immediate test method (cued

897 recall vs. multiple-choice meaning-to-word matching) on retention of new word meanings

898 learned through stories. A secondary aim was to rule out the possibility that the testing effect in

899 Experiment 2 was simply a practice effect due to having previously completed the same test, and

900 that retrieval practice can generalise to a different delayed test. We predicted that the results

901 would replicate the key finding from Experiment 2 of better long-term retention for items tested

902 immediately after training (regardless of testing method) than items not tested previously.

903 Additionally, we predicted that cued recall would be more beneficial for long-term retention of 
904 new word meanings than multiple-choice meaning-to-word matching as, according to the

905 retrieval effort hypothesis (Pyc \& Rawson, 2009), production tests that require more effortful

906 retrieval than recognition tests (Roediger \& Butler, 2011; Rowland, 2014) are more helpful for

907 retention. However, it was also possible that the multiple-choice meaning-to-word matching test

908 could result in better subsequent retention as this test provides participants with additional cues

909 that provide an additional learning opportunity (Marsh et al., 2007). Finally, it was possible that

910 the testing effect would not transfer across test tasks (Hogan \& Kintsch, 1971; Tran et al., 2014),

911 and so the benefit of each method of immediate test would only be seen for the delayed test of

912 the same type, in which case it could be characterised as more of a practice effect.

913 Experiment 3 was preregistered through the Open Science Framework; the preregistration

914 is available at https://osf.io/c59tz (Hulme \& Rodd, 2017, June 23). Any deviations from the

915 preregistration are noted in the Method and Results sections for this experiment. The materials,

916 data, and analysis scripts for Experiment 3 can be found on the Open Science Framework (OSF;

917 https://osf.io/eh2c6).

918

919 Method

920 Participants.

921 We aimed to recruit 96 participants for Experiment 3 in which participants were trained 922 on eight items (four per testing condition) in one of two groups (who had different immediate 923 tests), with eight experiment versions (12 participants per version). The sample size was

924 established in consideration of the previous experiments. While there were more items per cell

925 per participant in Experiment 3 than Experiment 2, the additional between-participants factor of 
926 test method meant that a similarly large sample was required to achieve comparable power in

927 this experiment.

928 Ninety-eight participants were included in the experiment (age: $M=33.7$ years, $S D=8.0$;

92964 female); we over-recruited by two participants when pseudorandomly assigning participants

930 to the experiment versions and kept these participants. Participants were recruited in the same

931 way as for Experiments 1 and 2. They gave their informed consent before taking part (by means

932 of ticking boxes in the online consent form) and were paid for their participation at the end of

933 each session ( $£ 4$ for session one and $£ 2$ for session two). The UCL Experimental Psychology

934 Ethics Committee granted ethical approval for the research (Ref: EP/2017/009).

935

An additional 18 participants took part in the first session but did not complete session

936 two by the deadline (within six hours of receiving the invitation for the delayed test) and were

937 excluded. A further thirty-five participants were excluded due to getting more than one of the

938 multiple-choice comprehension questions wrong in either of the stories they read (see

939 Experiment 1 Procedure). Seven further participants were excluded due to a technical issue

940 during data collection, and two participants were excluded for being outliers in their mean

941 reading speed (faster than 806.2 words per minute, $2 S D$ above the mean). Excluded participants

942 were replaced during recruitment.

943

944

Materials.

945 The stimuli for Experiment 3 were identical to those used in the previous experiments.

946 One additional different paraphrased version of each of the definition sentences was created so

947 that a differently worded definition would be presented in the immediate and delayed multiple- 
948 choice meaning-to-word matching tests to counteract any direct practice effects (see Table S3 for

949 the additional paraphrased definitions: https://osf.io/tnb94).

950

951

\section{Design.}

952

The experiment used a mixed design with two independent variables: immediate test

953

method (two levels: cued recall and meaning-to-word matching) was manipulated between

954

participants, and whether items were or were not previously tested (two levels: not previously

955

tested versus previously tested was manipulated within subjects. The dependent variables were

956

accuracy in cued recall of the new meanings and multiple-choice meaning-to-word matching,

957

measured at the delayed test time point.

958

There were eight versions of the experiment to ensure the stimuli were seen an even

959

number of times in each condition across participants. Participants were pseudorandomly

960

assigned to one of the eight versions of the experiment. As in Experiments 1 and 2, each

961

participant was trained on half the total number of stimuli (eight items per participant; two

962

separate stories). For the key factor of immediate test method, half of the participants $(N=49)$

963

were given a cued recall test of half of their items (four items) immediately after training, and the

other half of the participants $(N=48)$ were given a multiple-choice meaning-to-word matching

965 test of half of their items immediately after training. The items that were or were not tested

966 immediately following training were also counterbalanced across participants.

967

968

\section{Procedure.}

969 The first session of the experiment began with the incidental training procedure.

970 Participants first read one of the short stories; the procedure for this was identical to that of the 
971 previous experiments. They were then asked to rate how enjoyable and clear they found the 972 story, and answer some questions about their subjective reading style, which took around two

973 minutes - this served as a brief interval between the two stories. Participants then read a second

974 story. Immediately following training participants completed the same Mill Hill vocabulary test

975 as used in the previous experiments (Mill Hill Vocabulary Test, Set A: Multiple Choice: Buckner

976 et al., 1996; Raven et al., 1998) as a filler task. Participants were then given an immediate test of

977 half the items they had been trained on (four items, two from each story), which was either a

978 cued recall test or a multiple-choice meaning-to-word matching test. The items were tested in a

979 randomised order in both of the test tasks, with no feedback given to participants. In the

980 multiple-choice meaning-to-word matching test, only the four words that a participant was being

981 immediately tested on appeared as the four alternative responses to choose from for each test

982 item; the order of these was also randomised for each test item.

983 Exactly 24 hours after the first session of the experiment had been made available, the

984 participants were asked to take part in the second session of the experiment: the surprise delayed

985 test. Again participants were not aware of this delayed test beforehand; unfortunately 18

986 participants did not return to complete session two and were replaced during data collection.

987 Participants completed the delayed test an average of 24 hours and 31 minutes ( $S D=57$ mins;

988 range $=22 \mathrm{~h} 40 \mathrm{~m}-27 \mathrm{~h} 25 \mathrm{~m})$ after the training session. The tests used for the delayed test session

989 were the same as for the immediate test, but this time participants completed both tests: cued

990 recall of meanings followed by multiple-choice meaning-to-word matching. At the delayed test

991 participants were tested on all of the stimuli that they had been trained on (eight items). The

992 order of presentation of the items in each of the two tests was again randomised for each

993 participant. For the multiple-choice test, different paraphrased versions of the definition 
994 sentences were used to those that had appeared in the immediate test, and the order of the eight

995 words to choose from was randomised for each test item.

996

997 Results

998

Analysis procedure.

Responses on the cued recall and multiple-choice tests were coded for accuracy in the

1000 same way as for the previous experiments. The data were again analysed using logistic mixed effects models with the lme4 package (version 1.1-13; Bates et al., 2015) and R statistical software (version 3.3.3; R Core Team, 2017). Two models were created to analyse the results of the two delayed tests of cued recall and multiple-choice meaning-to-word matching separately.

1004 Contrasts for the fixed effects were defined using deviation coding for whether items were or 1005 were not immediately tested (not previously tested: -0.5 , previously tested: 0.5 ), and the 1006 immediate test method (cued recall: -0.5 , multiple-choice: 0.5 ), with the interaction coded by 1007 multiplying the contracts for these two factors. The model for the cued recall data used the 1008 maximal random effects structure, with by-participant and by-item random intercepts, a by1009 participants random slope for whether items were or were not previously tested, and by-items

1010 random slopes for whether items were or were not previously tested, method of immediate test,

1011 and the interaction. The model for the multiple-choice measure was simplified by removing the 1012 correlations between the random slopes and random intercepts (as recommended by Barr et al., 1013 2013).

1014 Following on from the main analysis, simple effects analyses were carried out to 1015 determine significance of whether items had or had not been immediately tested within each of 
1016 the two immediate test methods separately. All data and analysis scripts for this experiment are

1017 available via the Open Science Framework (https://osf.io/eh2c6).

1018

1019

\section{Cued recall of meanings.}

1020 The accuracy data for cued recall (measured in the delayed test session) are shown in

1021 Figure 5. Cued recall performance was low overall when items had not been tested immediately 1022 after training and was similar for the immediate cued recall group (26.5\%) and immediate 1023 multiple-choice meaning-to-word matching group (25.5\%): there was no significant main effect 1024 of immediate test method $\left[\chi^{2}(1)=0.47, p=.491\right]$. This is reassuring as it shows that the two 1025 groups of participants (who had different immediate test methods) performed similarly overall.

1026 There was a significant main effect of whether items were or were not immediately tested $\left[\chi^{2}(1)\right.$ $1027=23.73, p<.001]$ : performance was much higher when items had been tested immediately after 1028 training. Although accuracy appeared higher for the immediate multiple-choice group (58.3\%)

1029 than for the immediate cued recall group (49.5\%) when items had been previously tested, the 1030 interaction was non-significant $\left[\chi^{2}(1)=3.18, p=.074\right]$. The planned simple effects follow-up 1031 analysis showed that there was a significant effect of whether items were or were not 1032 immediately tested within the immediate cued recall group $\left[\chi^{2}(1)=8.25, p=.004\right]$, and also 1033 within the multiple-choice meaning-to-word matching group $\left[\chi^{2}(1)=25.10, p<.001 ; \alpha=.025\right]$. 1034

Figure 5. Experiment 3. Mean percentage of correct responses in the cued recall test 
1038 those whose immediate test was multiple-choice when items were or were not previously

1039 tested.

1040 Error bars show standard error of the means adjusted for the within-participants factor of whether

1041 items were or were not previously tested (Cousineau, 2005).

1042

1043

1044

Multiple-choice meaning-to-word matching.

The accuracy data for the multiple-choice meaning-to-word matching test (measured in

1045 the delayed test session) are shown in Figure 6. Performance on this test was much higher overall

1046 than on the cued recall test. Accuracy was significantly lower when items had not been tested

1047 immediately after training $\left[\chi^{2}(1)=14.54, p<.001\right]$, and there was no significant main effect of

1048 immediate test method $\left[\chi^{2}(1)=2.38, p=.123\right]$. Concerning a possible interaction between

1049 whether items were or were not immediately tested and the immediate test method, the simple

1050 means for accuracy were similar for the immediate cued recall group $(60.5 \%)$ and the immediate

1051 multiple-choice meaning-to-word matching group $(63.5 \%)$ when there was no previous test. This

1052 is again reassuring as is shows that the two groups of participants (who had different immediate

1053 test methods) performed similarly overall. Although the simple means for accuracy on items that

1054 had been tested previously appeared to be higher for the immediate multiple-choice group

$1055(78.6 \%)$ than for the immediate cued recall group (67.5\%), the interaction was non-significant

$1056\left[\chi^{2}(1)=2.48, p=.116\right]$. The planned simple effects follow-up analysis showed that the effect of

1057 whether items were or were not immediately tested was non-significant within the immediate

1058 cued recall group $\left[\chi^{2}(1)=3.31, p=.069\right]$. The effect was, however, significant within the

1059 multiple-choice meaning-to-word matching group $\left[\chi^{2}(1)=10.76, p=.001 ; \alpha=.025\right]$.

1060

Peer] reviewing PDF | (2020:11:55152:1:0:NEW 23 May 2021) 
[Figure 6.png]

1062 Figure 6. Experiment 3. Mean percentage of correct responses in the multiple-choice test measured at the delayed test for participants whose immediate test was cued recall, and for those whose immediate test was multiple-choice, when items were or were not previously tested.

1066 Error bars show standard error of the means adjusted for the within-participants factor of whether 1067 items were or were not previously tested (Cousineau, 2005).

\section{Discussion} after training significantly boosted retention of new word meanings learned incidentally through story reading as measured at the delayed tests 24 hours later. Importantly, Experiment 3 showed that testing memory immediately after training using either cued recall or multiple-choice alone was sufficient to result in a significant testing effect. This is consistent with studies that have found a testing effect arising from an immediate cued recall test (Karpicke \& Smith, 2012) or an immediate test using multiple-choice questions (Roediger \& Marsh, 2005). testing methods: the retention benefits following the immediate multiple-choice test were non-

1079 significantly larger than the immediate cued recall test. The simple effects showed that the 1080 immediate multiple-choice test significantly boosted performance on both of the delayed tests,

1081 while the immediate cued recall test only significantly enhanced performance on the delayed

1082 cued recall test but not on the delayed multiple-choice test (the effect was marginally significant 1083 at the uncorrected level). 
Finally, the immediate multiple-choice test enhanced delayed cued recall of the new word

1085

1086

1087

1088

1089

1090

1091

1092

1093

1094

1095

1096

1097

1098

1099

1100

1101

1102

1103

1104

1105

1106

meanings. This cross-task transfer effect suggests that the observed benefit is not simply due to

practising the same test previously. This demonstrates that knowledge retained from prior testing

can be flexibly applied to new contexts of retrieval, in line with the findings of Rohrer et al. (2010) and others.

\section{General discussion}

The present experiments investigated participants' ability to learn new word meanings from naturalistic story contexts. Specifically we (i) compared performance in this relatively incidental learning condition to a more conventional explicit learning paradigm and (ii) examined the role of testing memory after training in enhancing future retention of new word meanings.

\section{Incidental versus intentional learning}

In Experiment 1 and Experiment 2 participants learned new meanings for familiar words better under intentional learning conditions than incidentally through reading stories. These findings are in line with those of studies that have compared incidental and intentional learning in studies of L2 vocabulary learning (Hulstijn, 1992; Peters et al., 2009) and L1 vocabulary learning with adolescents (Konopak et al., 1987).

The intentional and incidental learning paradigms differed in several important ways, making it difficult to draw firm conclusions for the specific underlying cause of this difference. It may be driven by additional attentional focus on word meanings in the intentional learning condition, while in the incidental learning condition participants' attention was directed towards 
1107 other aspects of the rich narrative context of the stories. The two learning paradigms also differed

1108 in the spacing of the words, which were systematically spaced throughout the intentional

1109 learning task. In the stories, on the other hand, the new word meanings appeared at naturally-

1110 occurring intervals such that some exposures occurred relatively close together. Spacing stimuli

1111 apart has been widely shown to aid learning (for review see: Dempster, 1996).

1112 Additionally, there is the possibility of an internal testing effect within the intentional

1113 learning task. The multiple-choice meaning-to-word matching portion of the intentional learning

1114 task was similar to the multiple-choice meaning-to-word matching task used in the testing phase,

1115 which produced a testing effect on its own in Experiment 3. The multiple-choice training task

1116 also included simple feedback on performance ("correct" or "incorrect"), and feedback can

1117 enhance the benefit of tests for future retention. The trend in the data of Experiment 2 towards a

1118 larger testing effect for the incidental learning condition could possibly be because the

1119 intentional learning condition already involved a limited testing effect.

1120 As well as the overall differences in performance between learning conditions

1121 immediately after training, there were also differences in longer-term retention. After 24 hours,

1122 participants in Experiment 1 (and non-significantly in Experiment 2) had forgotten some of the

1123 new word meanings learned under intentional conditions, but there was very little forgetting of

1124 items learned incidentally across both experiments. In Experiment 2 the trend for reduced

1125 forgetting of items learned under incidental conditions was present regardless of an immediate

1126 test. The significant interaction between day and learning condition in Experiment 1 provides

1127 evidence for a difference in the amount of forgetting: word meanings learned incidentally,

1128 although harder to learn initially, may be forgotten less quickly than those learned under

1129 intentional conditions. This is possibly due to the more semantically rich context of the stories 
1130 providing participants with additional and more varied cues, which are advantageous for later

1131 retrieval of the new word meanings, or due to higher engagement as the stories are more

1132 enjoyable. An alternative possibility is that this difference is a function of the initial learning

1133 level as performance in the intentional learning condition was higher and so had further to fall.

1134 Another possibility is that memory consolidation during sleep may have played a role in

1135 preferentially strengthening the weaker memory traces of items acquired through incidental

1136 conditions (Drosopoulos et al., 2007). Nevertheless, while intentional learning conditions were

1137 better for more efficient acquisition, incidental learning may lead to less forgetting of word

1138 meanings over time. However, replication of the latter finding is warranted in future research in a

1139 design that matches on initial performance level between the different learning conditions. This

1140 may also help to determine whether the observed changes in performance over time reflect real

1141 differences in forgetting or differences in the two conditions in terms of different sensitivity to

1142 recall thresholds following the immediate test (see Kornell et al., 2011 for a discussion). Future

1143 replication of this finding is also important given the non-significant interaction between learning

1144 condition and immediate versus delayed first test in Experiment 2.

1145

\section{The testing effect}

1147 A large overall testing effect was found in both Experiment 2 and Experiment 3: retrieval 1148 practice following initial exposure boosted retention of new meanings for familiar words. Cued

1149 recall of the new word meanings was boosted by $28.8 \%$ for the incidental learning condition and

$1150 \quad 10.6 \%$ for the intentional learning condition in Experiment 2. This effect therefore likely

1151 explains the high levels of cued recall and multiple-choice accuracy in Experiment 1 after one

1152 day, and in Hulme et al.'s (2019) study after seven days. This finding adds to the growing 
1153 literature highlighting the role of testing in aiding vocabulary learning. A possible alternative

1154 explanation for this finding is that testing may bias participants towards selectively remembering

1155 tested items, so the effect may be driven by the cost to the untested items. Relatedly, research has

1156 shown that the retention of selected memories can be modulated after learning using simple

1157 verbal instructions on their future importance (van Dongen et al., 2012). However, several

1158 studies in the literature using a between-subjects design (e.g., Experiment 2 of Roediger \&

1159 Karpicke, 2006a) have demonstrated that the practice of testing enhances learning, rather than

1160 just biasing which items are remembered.

1161 The testing effect in Experiment 2 was elicited with both a cued recall and multiple-

1162 choice test immediately after training. However, the findings of Experiment 3 illustrated that

1163 either a cued recall test or a multiple-choice test alone was sufficient to produce a significant

1164 testing effect following incidental learning through story reading. There was no clear evidence

1165 that either of the two testing methods was superior to the other for enhancing memory retention,

1166 although the retention benefits for the immediate multiple-choice test were non-significantly

1167 larger than for the cued recall test. Previous research has shown cued recall (short answer

1168 questions) to be more helpful for memory retention in some contexts (Duchastel, 1981;

1169 McDaniel, Anderson, et al., 2007; McDaniel, Roediger, et al., 2007). However, recent research

1170 has suggested that the relative benefit of the testing method may depend on the type of

1171 information being learned. Nakata (2016) found that recall was most helpful for acquiring novel

1172 words' orthography (spelling), whereas recognition was more beneficial otherwise.

1173 Despite the growing body of research on the benefits of retrieval practice for retention,

1174 the neurocognitive mechanisms underlying the testing effect remain somewhat unclear (Antony

1175 et al., 2017). Influential models of word learning have not yet provided an account of the testing 
1176 effect. The Complementary Learning Systems (CLS) model of word learning, for example,

1177 describes how word forms are initially encoded into episodic memory in the hippocampus, and

1178 are integrated into semantic memory in the neocortex following a period of offline consolidation,

1179 such as during sleep (Davis \& Gaskell, 2009). However, this model does not account for the

1180 effect of conscious retrieval on memory for new words and their meanings. Antony et al. (2017)

1181 recently suggested that a similar mechanism may underlie both offline consolidation and the

1182 testing effect, which may provide a fast track to consolidation. They argue that retrieval practice

1183 brings about the formation of flexible hippocampal-neocortical representations through the

1184 online reactivation of related knowledge (Antony et al., 2017). The testing effect is therefore

1185 important to consider in conjunction with offline consolidation processes to garner a full picture

1186 of how novel word meanings are remembered. Future research should explore whether the

1187 testing effect involves a similar mechanism as unconscious offline learning processes, thus

1188 providing a fast track to consolidation.

1189 The findings of the present experiments have important methodological implications for

1190 studies of word learning. The enhancing effects of retrieval practice on memory are clearly

1191 shown here, and in other previous research. Studies considering the impact of factors such as the

1192 role of sleep for consolidation should (and do) consider this important aspect. For example,

1193 Henderson et al. (2015) compared adults' and children's explicit memory of new words using

1194 cued recall and recognition tests administered both immediately and 24 hours later. They note

1195 that for both adults and children "explicit phonological memory was enhanced after off-line

1196 consolidation" p.413 (Henderson et al., 2015). However, this finding could also, at least in part,

1197 be attributable to a testing effect, as the 24-hour tests repeated the 0-hour tests that participants

1198 completed immediately after training. Nevertheless, other studies in this field have isolated 
1199 effects of sleep from effects of testing using alternative designs, including train twice, test once

1200 (e.g., Weighall et al., 2017), and AM-PM designs to compare 12-hour periods associated with

1201 wake and sleep (e.g., Henderson et al., 2012; James et al., 2020). The testing effect is therefore

1202 an important consideration for studies of the cognitive mechanisms underlying vocabulary

1203 learning and retention that include repeated testing of trained words. Studies of sleep and

1204 vocabulary learning would benefit from using designs that avoid having multiple test sessions.

1205 For example, training different items at different times and testing all items in one final session

1206 (e.g., Experiment 1 of Tamminen \& Gaskell, 2013), or using a between-groups design to

1207 compare between two different times of test (e.g., Experiment 1 of Tamminen et al., 2015)

1208 avoids contaminating results of potential consolidation with those of a testing effect.

1209 The testing effect has previously been shown to generalise to educational settings. For

1210 example, Roediger et al. (2011) found that repeated testing of real course content with multiple-

1211 choice (and some short-answer tests) successfully boosted middle school students' grades on

1212 their social studies course. A similar study with a middle school science class (McDaniel et al.,

1213 2011) found that multiple-choice tests gave large gains (13-25\%) in learning and retention,

1214 assessed by end-of-unit exams, especially when tests were taken closer to exam time. Similar

1215 benefits of retrieval practice have been seen for college students (McDaniel, Anderson, et al.,

1216 2007; McDaniel, Roediger, et al., 2007), and Larsen et al. (2008) have advocated the use of test-

1217 enhanced learning in medical education. Our findings in Experiment 2 and Experiment 3 have

1218 important practical implications for vocabulary learning. Students learning vocabulary

1219 incidentally from reading storybooks or textbooks can benefit from being tested following initial

1220 encounters with new word meanings. Testing appears to be effective using either cued recall or

1221 multiple-choice methods, so incorporating it as part of a strategy for efficient vocabulary 
1222 learning could be easy to implement. Tests are often considered solely as tools to assess learning,

1223 however they also provide an important opportunity for additional learning and reinforcement of

1224 knowledge.

1225

\section{Conclusions}

The first two experiments confirmed that new word meanings are learned more

1228 efficiently under intentional learning conditions than incidentally through story reading.

1229 However, there was also some evidence of less forgetting of items learned through stories,

1230 suggesting that word meanings learned in a more semantically rich context could be retained

1231 better. The second two experiments showed that testing memory aids retention of new word

1232 meanings acquired under either incidental or intentional learning conditions. Both cued recall

1233 and recognition (multiple-choice) tests enhanced retention, but multiple-choice tests gave non-

1234 significantly better performance, even with no feedback. Furthermore the testing effect

1235 transferred across test tasks: immediate multiple-choice meaning-to-word matching improved

1236 accuracy on the delayed cued recall test, so the effect is not restricted to benefitting the same test.

1237 The present study has demonstrated that testing memory following initial exposure is a

1238 powerful way to improve learning and long-term retention of vocabulary knowledge.

1239 Importantly, we found that retrieval practice benefitted vocabulary retention from different

1240 learning conditions and using different methods of immediate test. The vast majority of new

1241 vocabulary is learned through reading from mid-childhood onwards. Test-enhanced learning

1242 could therefore be particularly useful if implemented during vocabulary development to boost

1243 children's vocabulary gains from story reading. 
The authors would like to thank Helen Moss and Johan Heemskerk for authoring the used with the stories and assisting with coding the data. The authors would also like to thank Dr

Eva Poort for providing feedback on an earlier version of this article.

\section{References}

1251 Antony, J. W., Ferreira, C. S., Norman, K. A., \& Wimber, M. (2017). Retrieval as a fast route to 1252 memory consolidation. Trends in Cognitive Sciences, 21(8), 573-576.

1253 https://doi.org/10.1016/j.tics.2017.05.001

1254 Armstrong, R., Arnott, W., Copland, D. A., McMahon, K., Khan, A., Najman, J. M., \& Scott, J.

1255 G. (2017). Change in receptive vocabulary from childhood to adulthood: associated mental

1256 health, education and employment outcomes. International Journal of Language and

1257 Communication Disorders, 52(5), 561-572. https://doi.org/10.1111/1460-6984.12301

1258 Barr, D. J., Levy, R., Scheepers, C., \& Tily, H. J. (2013). Random effects structure for

1259 confirmatory hypothesis testing: Keep it maximal. Journal of Memory and Language, 68(3),

$1260 \quad$ 255-278. https://doi.org/10.1016/j.jml.2012.11.001

1261 Bates, D., Mächler, M., Bolker, B., \& Walker, S. (2015). Fitting linear mixed-effects models

1262 using lme4. Journal of Statistical Software, 67(1), 1-48.

1263 https://doi.org/10.18637/jss.v067.i01

1264 Bates, D., Mächler, M., Bolker, B., \& Walker, S. (2016). Ime4: Linear mixed-effects models

1265 using "eigen” and s4. [Software Manual]. https://cran.r-

$1266 \quad$ project.org/web/packages/lme4/lme4.pdf

1267 Batterink, L., \& Neville, H. (2011). Implicit and explicit mechanisms of word learning in a 
narrative context: An event-related potential study. Journal of Cognitive Neuroscience, 23(11), 3181-3196. https://doi.org/10.1162/jocn_a_00013

1270 Betts, H. N., Gilbert, R. A., Cai, Z. G., Okedara, Z. B., \& Rodd, J. M. (2018). Retuning of

1271 lexical-semantic representations: Repetition and spacing effects in word-meaning priming.

1272 Journal of Experimental Psychology: Learning Memory and Cognition, 44(7), 1130-1150.

1273 https://doi.org/10.1037/xlm0000507

1274 Blything, L. P., Hardie, A., \& Cain, K. (2020). Question Asking During Reading Comprehension

1275 Instruction: A Corpus Study of How Question Type Influences the Linguistic Complexity of

1276 Primary School Students’ Responses. Reading Research Quarterly, 55(3), 443-472.

1277 https://doi.org/10.1002/rrq.279

1278 Buckner, R. L., Bandettini, P. A., O’Craven, K. M., Savoy, R. L., Petersen, S. E., Raichle, M. E.,

1279 \& Rosen, B. R. (1996). Detection of cortical activation during averaged single trials of a

1280 cognitive task using functional magnetic resonance imaging. Proceedings of the National

1281 Academy of Sciences, 93(25), 14878-14883. https://doi.org/10.1073/pnas.93.25.14878

1282 Butler, A. C. (2010). Repeated testing produces superior transfer of learning relative to repeated

1283 studying. Journal of Experimental Psychology: Learning Memory and Cognition, 36(5),

1284 1118-1133. https://doi.org/10.1037/a0019902

1285 Butler, A. C., Marsh, E. J., Goode, M. K., \& Roediger, H. L. (2006). When additional multiple-

1286 choice lures aid versus hinder later memory. Applied Cognitive Psychology, 20(7), 941-

1287 956. https://doi.org/10.1002/acp.1239

1288 Cain, K., \& Oakhill, J. (2014). Reading comprehension and vocabulary: Is vocabulary more

1289 important for some aspects of comprehension? L'Annee Psychologique, 114(4), 647-662.

1290 https://doi.org/10.4074/S0003503314004035 
1291 Carpenter, S. K. (2009). Cue Strength as a Moderator of the Testing Effect: The Benefits of

1292 Elaborative Retrieval. Journal of Experimental Psychology: Learning Memory and

1293 Cognition, 35(6), 1563-1569. https://doi.org/10.1037/a0017021

1294 Cousineau, D. (2005). Confidence intervals in within-subject designs: A simpler solution to

1295 Loftus and Masson's method. Tutorials in Quantitative Methods for Psychology, 1(1), 42-

1296 45. https://doi.org/10.20982/tqmp.01.1.p042

1297 Damer, E., \& Bradley, P. (2014). Prolific Academic [Computer Software].

1298 https://www.prolific.ac/

1299 Davis, M. H., \& Gaskell, M. G. (2009). A complementary systems account of word learning:

$1300 \quad$ Neural and behavioural evidence. Philosophical Transactions of the Royal Society of

$1301 \quad$ London. Series B, Biological Sciences, 364, 3773-3800.

1302 https://doi.org/10.1098/rstb.2009.0111

1303 Dempster, F. N. (1996). Distributing and managing the conditions of encoding and practice. In E.

1304 L. Bjork \& R. A. Bjork (Eds.), Handbook of perception and cognition: Memory (pp. 31-

1305 344). Academic Press.

1306 Drosopoulos, S., Schulze, C., Fischer, S., \& Born, J. (2007). Sleep's Function in the Spontaneous

1307 Recovery and Consolidation of Memories. Journal of Experimental Psychology: General,

1308 136(2), 169-183. https://doi.org/10.1037/0096-3445.136.2.169

1309 Duchastel, P. C. (1981). Retention of prose following testing with different types of tests.

1310 Contemporary Educational Psychology, 6(3), 217-226. https://doi.org/10.1016/0361-

$1311 \quad 476 X(81) 90002-3$

1312 Eligio, R. B., \& Kaschak, M. P. (2021). Gaming experience affects the interpretation of

1313 ambiguous words. PLoS ONE, 15 (12 December), e0243512. 
1314 https://doi.org/10.1371/journal.pone.0243512

1315 Fritz, C. O., Morris, P. E., Acton, M., Voelkel, A. R., \& Etkind, R. (2007). Comparing and

1316 combining retrieval practice and the keyword mnemonic for foreign vocabulary learning.

1317 Applied Cognitive Psychology, 21(4), 499-526. https://doi.org/10.1002/acp.1287

1318 Gaskell, M. G., Cairney, S. A., \& Rodd, J. M. (2019). Contextual priming of word meanings is

$1319 \quad$ stabilized over sleep. Cognition, 182, 109-126.

1320 https://doi.org/10.1016/j.cognition.2018.09.007

1321 Gilbert, R. A., Davis, M. H., Gareth Gaskell, M., \& Rodd, J. M. (2018). Listeners and readers

1322 generalize their experience with word meanings across modalities. Journal of Experimental

1323 Psychology: Learning, Memory, and Cognition, 44(10), 1533-1561.

$1324 \quad$ https://doi.org/10.1037/xlm0000532

1325 Gilbert, R. A., Davis, M. H., Gaskell, M. G., \& Rodd, J. M. (2021). The relationship between

1326 sentence comprehension and lexical-semantic retuning. Journal of Memory and Language,

$1327 \quad 116,104188$. https://doi.org/10.1016/j.jml.2020.104188

1328 Godfroid, A., Ahn, J., Choi, I., Ballard, L., Cui, Y., Johnston, S., Lee, S., Sarkar, A., \& Yoon,

1329 H.-J. (2017). Incidental vocabulary learning in a natural reading context: An eye-tracking

$1330 \quad$ study. Bilingualism: Language and Cognition, 21(3), 563-584.

$1331 \quad$ https://doi.org/10.1017/S1366728917000219

1332 Goossens, N. A. M. C., Camp, G., Verkoeijen, P. P. J. L., \& Tabbers, H. K. (2014). The effect of

1333 retrieval practice in primary school vocabulary learning. Applied Cognitive Psychology,

$133428(1), 135-142$. https://doi.org/10.1002/acp.2956

1335 Goossens, N. A. M. C., Camp, G., Verkoeijen, P. P. J. L., Tabbers, H. K., \& Zwaan, R. A.

1336 (2014). The benefit of retrieval practice over elaborative restudy in primary school 
vocabulary learning. Journal of Applied Research in Memory and Cognition, 3(3), 177-182.

1338 https://doi.org/10.1016/j.jarmac.2014.05.003

1339 Henderson, L. M., Devine, K., Weighall, A., \& Gaskell, G. (2015). When the daffodat flew to

1340 the intergalactic zoo: Off-line consolidation is critical for word learning from stories.

1341 Developmental Psychology, 51(3), 406-417. https://doi.org/10.1037/a0038786

1342 Henderson, L. M., Weighall, A. R., Brown, H., \& Gaskell, M. G. (2012). Consolidation of

1343 vocabulary is associated with sleep in children. Developmental Science, 15(5), 674-687.

$1344 \quad$ https://doi.org/10.1111/j.1467-7687.2012.01172.x

1345 Hogan, R. M., \& Kintsch, W. (1971). Differential effects of study and test trials on long-term

1346 recognition and recall. Journal of Verbal Learning and Verbal Behavior, 10(5), 562-567.

1347 https://doi.org/10.1016/S0022-5371(71)80029-4

1348 Hulme, R. C., Barsky, D., \& Rodd, J. M. (2019). Incidental Learning and Long-Term Retention

1349 of New Word Meanings From Stories: The Effect of Number of Exposures. Language

1350 Learning, 69(1), 18-43. https://doi.org/10.1111/lang.12313

1351 Hulme, R. C., \& Rodd, J. M. (2016). The testing effect in long-term retention of novel meanings

1352 for known words learned through incidental and intentional means. https://osf.io/e5zmk/

1353 Hulme, R. C., \& Rodd, J. M. (2017). The impact of test method on the testing effect in long-term

1354 retention of new word meanings learned incidentally from stories. https://osf.io/c59tz/

1355 Hulstijn, J. H. (1992). Retention of inferred and given word meanings: Experiments in incidental

1356 vocabulary learning. In P. J. L. Arnaud \& H. Béjoint (Eds.), Vocabulary and applied

1357 linguistics (pp. 113-125). Macmillan. https://doi.org/10.1007/978-1-349-12396-4_11

1358 Hulstijn, J. H. (2003). Incidental and intentional learning. In C. J. Doughty \& M. H. Long (Eds.),

1359 The handbook of second language acquisition (pp. 349-381). Blackwell. 
1360 https://doi.org/10.1002/9780470756492.ch12

1361 James, E., Gaskell, M. G., \& Henderson, L. M. (2020). Sleep-dependent consolidation in

1362 children with comprehension and vocabulary weaknesses: it'll be alright on the night?

1363 Journal of Child Psychology and Psychiatry, 61(10), 1104-1115.

1364 https://doi.org/10.1111/jcpp.13253

1365 Kang, S. H. K., Mcdermott, K. B., Roediger, H. L., \& Kang, S. (2007). Test format and

1366 corrective feedback modify the effect of testing on long-term retention. European Journal

1367 of Cognitive Psychology, 19(4-5), 528-558. https://doi.org/10.1080/09541440601056620

1368 Karpicke, J. D., \& Roediger, H. L. (2007). Expanding retrieval practice promotes short-term

1369 retention, but equally spaced retrieval enhances long-term retention. Journal of

1370 Experimental Psychology: Learning, Memory, and Cognition, 33(4), 704-719.

$1371 \quad$ https://doi.org/10.1037/0278-7393.33.4.704

1372 Karpicke, J. D., \& Roediger, H. L. (2008). The critical importance of retrival for learning.

1373 Science, 319(5865), 966-968. https://doi.org/10.1126/science.1152408

1374 Karpicke, J. D., \& Smith, M. A. (2012). Separate mnemonic effects of retrieval practice and

1375 elaborative encoding. Journal of Memory and Language, 67(1), 17-29.

1376 https://doi.org/10.1016/J.JML.2012.02.004

1377 Konopak, B., Sheard, C., Longman, D., Lyman, B., Slaton, E., Atkinson, R., \& Thames, D.

1378 (1987). Incidental versus intentional word learning from context. Reading Psychology: An

1379 International Quarterly, 8(1), 7-21. https://doi.org/10.1080/0270271870080103

1380 Kornell, N., Bjork, R. A., \& Garcia, M. A. (2011). Why tests appear to prevent forgetting: A

1381 distribution-based bifurcation model. Journal of Memory and Language, 65(2), 85-97.

$1382 \quad$ https://doi.org/10.1016/j.jml.2011.04.002 
1383 Larsen, D. P., Butler, A. C., \& Roediger, H. L. (2008). Test-enhanced learning in medical

1384 education. Medical Education, 42(10), 959-966. https://doi.org/10.1111/j.1365-

$1385 \quad 2923.2008 .03124 . x$

1386 Lehmann, M. (2007). Is intentional or incidental vocabulary learning more effective? The

1387 International Journal of Foreign Language Teaching, 3(1), 23-28.

1388 Maciejewski, G., \& Klepousniotou, E. (2020). Disambiguating the ambiguity disadvantage

1389 effect: Behavioral and electrophysiological evidence for semantic competition. Journal of

1390 Experimental Psychology: Learning Memory and Cognition, 46(9), 1682-1700.

$1391 \quad$ https://doi.org/10.1037/xlm0000842

1392 Maciejewski, G., Rodd, J. M., Mon-Williams, M., \& Klepousniotou, E. (2020). The cost of

1393 learning new meanings for familiar words. Language, Cognition and Neuroscience, 35(2),

$1394 \quad$ 188-210. https://doi.org/10.1080/23273798.2019.1642500

1395 Marsh, E. J., Roediger, H. L., Bjork, R. A., \& Bjork, E. L. (2007). The memorial consequences

1396 of multiple-choice testing. Psychonomic Bulletin and Review, 14(2), 194-199.

1397 https://link.springer.com/content/pdf/10.3758/BF03194051.pdf

1398 Mason, B., \& Krashen, S. (2004). Is form-focused vocabulary instruction worth while? RELC

1399 Journal, 35(2), 179-185. https://doi.org/10.1177/003368820403500206

1400 McDaniel, M. A., Agarwal, P. K., Huelser, B. J., McDermott, K. B., \& Roediger, H. L. (2011).

1401 Test-Enhanced Learning in a Middle School Science Classroom: The Effects of Quiz

1402 Frequency and Placement. Journal of Educational Psychology, 103(2), 399-414.

1403 https://doi.org/10.1037/a0021782

1404 McDaniel, M. A., Anderson, J. L., Derbish, M. H., \& Morrisette, N. (2007). Testing the testing 1405 effect in the classroom. European Journal of Cognitive Psychology, 19(4-5), 494-513. 
1406 https://doi.org/10.1080/09541440701326154

1407 McDaniel, M. A., Roediger, H. L., \& McDermott, K. B. (2007). Generalizing test-enhanced

1408 learning from the laboratory to the classroom. Psychonomic Bulletin and Review, 14(2),

1409 200-206. https://link.springer.com/content/pdf/10.3758/BF03194052.pdf

1410 Nagy, W. E., Anderson, R. C., \& Herman, P. A. (1987). Learning Word Meanings From Context

1411 During Normal Reading. American Educational Research Journal Summer, 24(2), 237-

1412 270. http://journals.sagepub.com/doi/pdf/10.3102/00028312024002237

1413 Nagy, W. E., Herman, P. A., \& Anderson, R. C. (1985). Learning words from context. Reading

1414 Research Quarterly, 20(2), 233-253. http://www.jstor.org/stable/747758

1415 Nakata, T. (2016). Effects of retrieval formats on second language vocabulary learning.

1416 International Review of Applied Linguistics in Language Teaching, 54(3), 257-289.

1417 https://doi.org/10.1515/iral-2015-0022

1418 Nation, K. (2017). Nurturing a lexical legacy: Reading experience is critical for the development

1419 of word reading skill. Npj Science of Learning, 2(1), 3. https://doi.org/10.1038/s41539-017-

$1420 \quad 0004-7$

1421 Pashler, H., Cepeda, N. J., Wixted, J. T., \& Rohrer, D. (2005). When does feedback facilitate

1422 learning of words? Journal of Experimental Psychology: Learning Memory and Cognition,

$1423 \quad 31(1), 3-8$. https://doi.org/10.1037/0278-7393.31.1.3

1424 Pellicer-Sánchez, A. (2016). Incidental L2 vocabulary acquisition from and while reading.

1425 Studies in Second Language Acquisition, 38(1), 97-130.

1426 https://doi.org/10.1017/S0272263115000224

1427 Peters, E., Hulstijn, J. H., Sercu, L., \& Lutjeharms, M. (2009). Learning L2 German vocabulary

1428 through reading: The effect of three enhancement techniques compared. Language 
1430 Pyc, M. A., \& Rawson, K. A. (2009). Testing the retrieval effort hypothesis: Does greater

1431 difficulty correctly recalling information lead to higher levels of memory? Journal of

1432 Memory and Language, 60(4), 437-447. https://doi.org/10.1016/j.jml.2009.01.004

1433 Qualtrics. (2015). Qualtrics Survey Software. Qualtrics. https://www.qualtrics.com

1434 R Core Team. (2017). R: A language and environment for statistical computing. R Foundation

1435 for Statistical Computing, Vienna, Austria. https://www.r-project.org/

1436 Raven, J., Raven, J. C., \& Court, J. H. (1998). Manual for Raven's progressive matrices and

1437 vocabulary scales. Section 5: The Mill Hill vocabulary scale. Harcourt Assessment.

1438 Rodd, J. M. (2018). Lexical Ambiguity. In S.-A. Rueschemeyer \& M. G. Gaskell (Eds.), Oxford

1439 Handbook of Psycholinguistics (2nd ed., pp. 96-117). Oxford University Press.

1440 Rodd, J. M. (2020). Settling Into Semantic Space: An Ambiguity-Focused Account of Word-

1441 Meaning Access. Perspectives on Psychological Science, 15(2), 411-427.

$1442 \quad$ https://doi.org/10.1177/1745691619885860

1443 Rodd, J. M., Berriman, R., Landau, M., Lee, T., Ho, C., Gaskell, M. G., \& Davis, M. H. (2012).

1444 Learning new meanings for old words: Effects of semantic relatedness. Memory \&

1445 Cognition, 40(7), 1095-1108. https://doi.org/10.3758/s13421-012-0209-1

1446 Rodd, J. M., Cai, Z. G., Betts, H. N., Hanby, B., Hutchinson, C., \& Adler, A. (2016). The impact

1447 of recent and long-term experience on access to word meanings: Evidence from large-scale

1448 internet-based experiments. Journal of Memory and Language, 87, 16-37.

1449 https://doi.org/10.1016/J.JML.2015.10.006

1450 Rodd, J. M., Gaskell, G., \& Marslen-Wilson, W. (2002). Making sense of semantic ambiguity:

1451 Semantic competition in lexical access. Journal of Memory and Language, 46(2), 245-266. 
1453 Rodd, J. M., Lopez Cutrin, B., Kirsch, H., Millar, A., \& Davis, M. H. (2013). Long-term priming 1454 of the meanings of ambiguous words. Journal of Memory and Language, 68(2), 180-198.

1455 https://doi.org/10.1016/j.jml.2012.08.002

1456 Roediger, H. L., Agarwal, P. K., McDaniel, M. A., \& McDermott, K. B. (2011). Test-Enhanced

1457 Learning in the Classroom: Long-Term Improvements From Quizzing. Journal of

1458 Experimental Psychology: Applied, 17(4), 382-395. https://doi.org/10.1037/a0026252

1459 Roediger, H. L., \& Butler, A. C. (2011). The critical role of retrieval practice in long-term

1460 retention. Trends in Cognitive Sciences, 15(1), 20-27.

$1461 \quad$ https://doi.org/10.1016/j.tics.2010.09.003

1462 Roediger, H. L., \& Karpicke, J. D. (2006a). Test-enhanced learning: Taking memory tests

1463 improves long-term retention. Psychological Science, 17(3), 249-255.

$1464 \quad$ https://doi.org/10.1111/j.1467-9280.2006.01693.x

1465 Roediger, H. L., \& Karpicke, J. D. (2006b). The power of testing memory: Basic research and

1466 implications for educational practice. Perspectives on Psychological Science, 1(3), 181-

1467 210. https://doi.org/10.1111/j.1745-6916.2006.00012.x

1468 Roediger, H. L., \& Marsh, E. J. (2005). The positive and negative consequences of multiple-

1469 choice testing. Journal of Experimental Psychology: Learning, Memory, and Cognition,

$1470 \quad 31(5), 1155-1159$. https://doi.org/10.1037/0278-7393.31.5.1155

1471 Rohrer, D., Taylor, K., \& Sholar, B. (2010). Tests enhance the transfer of learning. Journal of

1472 Experimental Psychology: Learning Memory and Cognition, 36(1), 233-239.

1473 https://doi.org/10.1037/a0017678

1474 Rowland, C. A. (2014). The effect of testing versus restudy on retention: A meta-analytic review 
1475 of the testing effect. Psychological Bulletin, 140(6), 1432-1463.

1476 https://doi.org/10.1037/a0037559

1477 Saragi, T., Nation, I. S. P., \& Meister, G. F. (1978). Vocabulary learning and reading. System,

$1478 \quad 6(2), 72-78 . \mathrm{https} / / /$ doi.org/10.1016/0346-251X(78)90027-1

1479 Tamminen, J., Davis, M. H., \& Rastle, K. (2015). From specific examples to general knowledge

$1480 \quad$ in language learning. Cognitive Psychology, 79, 1-39.

$1481 \quad$ https://doi.org/10.1016/j.cogpsych.2015.03.003

1482 Tamminen, J., \& Gaskell, M. G. (2013). Novel word integration in the mental lexicon: evidence

1483 from unmasked and masked semantic priming. Quarterly Journal of Experimental

1484 Psychology (2006), 66(5), 1001-1025. https://doi.org/10.1080/17470218.2012.724694

1485 Toppino, T. C., \& Cohen, M. S. (2009). The testing effect and the retention interval: Questions

1486 and answers. Experimental Psychology, 56, 252-257. https://doi.org/10.1027/1618-

$1487 \quad 3169.56 .4 .252$

1488 Tran, R., Rohrer, D., \& Pashler, H. (2014). Retrieval practice: The lack of transfer to deductive

1489 inferences. Psychonomic Bulletin \& Review, 22(1), 135-140.

$1490 \quad$ https://doi.org/10.3758/s13423-014-0646-X

1491 van den Broek, G. S. E., Takashima, A., Segers, E., Fernández, G., \& Verhoeven, L. (2013).

1492 Neural correlates of testing effects in vocabulary learning. NeuroImage, 78, 94-102.

1493 https://doi.org/10.1016/j.neuroimage.2013.03.071

1494 van den Broek, G. S. E., Takashima, A., Segers, E., \& Verhoeven, L. (2018). Contextual richness

1495 and word learning: Context enhances comprehension but retrieval enhances retention.

1496 Language Learning, 68(2), 546-585. https://doi.org/10.1111/lang.12285

1497 van Dongen, E. V., Thielen, J.-W., Takashima, A., Barth, M., \& Fernández, G. (2012). Sleep 
1498 Supports Selective Retention of Associative Memories Based on Relevance for Future

1499 Utilization. PLoS ONE, 7(8), e43426. https://doi.org/10.1371/journal.pone.0043426

1500 Weighall, A. R., Henderson, L. M., Barr, D. J., Cairney, S. A., \& Gaskell, M. G. (2017). Eye1501 tracking the time-course of novel word learning and lexical competition in adults and 1502 children. Brain and Language, 167, 13-27. https://doi.org/10.1016/j.bandl.2016.07.010 


\section{Figure 1}

Experiment 1. Mean percentage of correct responses on the cued recall test for each learning condition, when tested on day one (immediately after learning) and 24 hours later $(N=31)$.

The LME analyses were carried out on the raw binary accuracy data, however mean percentage accuracy data are displayed in the graphs for ease of interpretation. Error bars show standard errors for the means, adjusted for the within-participant design (Cousineau, 2005).

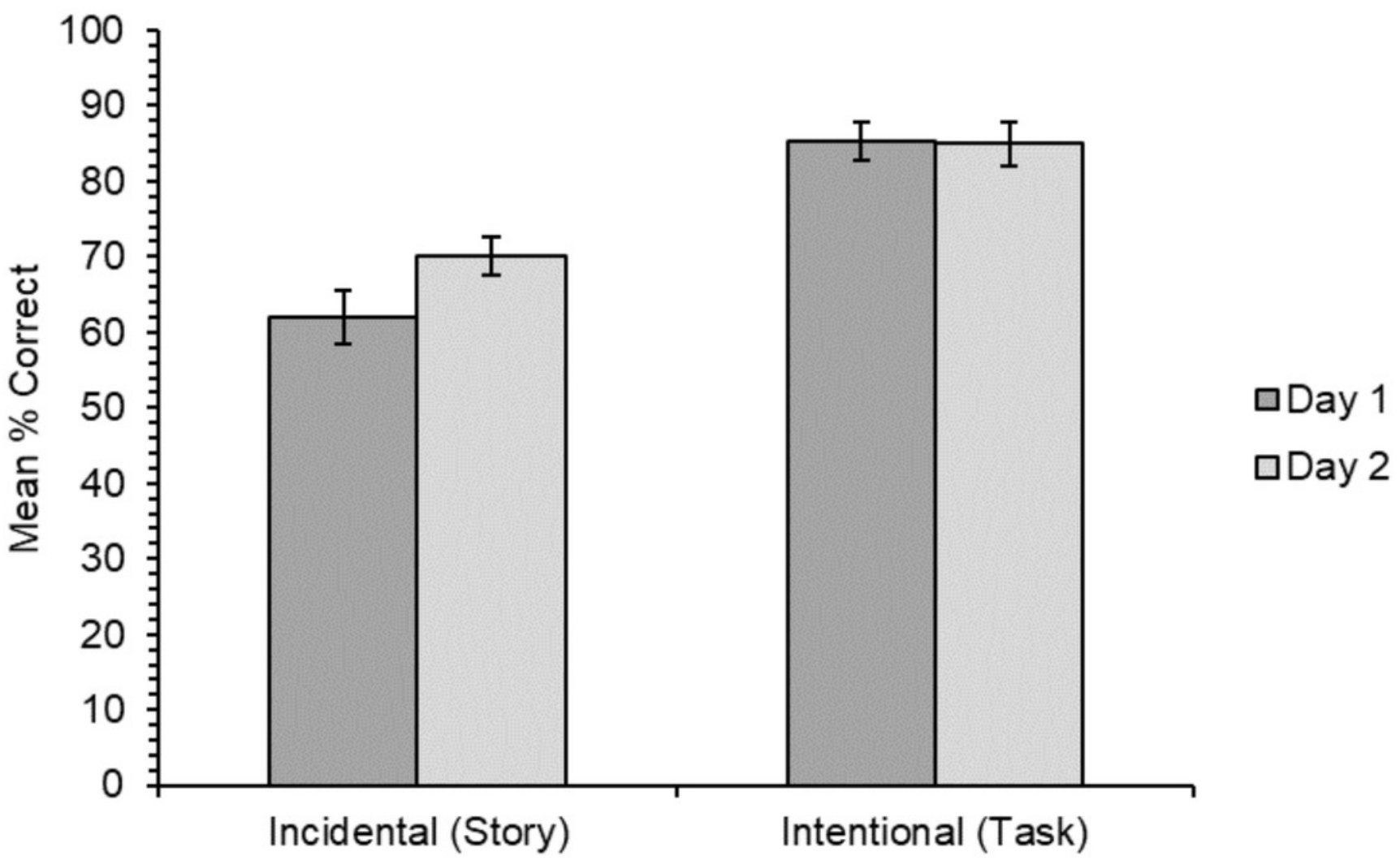


Figure 2

Experiment 1. Mean percentage of correct responses on the multiple-choice test for each learning condition, when tested on day one (immediately after learning) and day two (24 hours later; $N=31$ ).

Error bars show standard errors for the means, adjusted for the within-participant factor of learning condition (Cousineau, 2005).

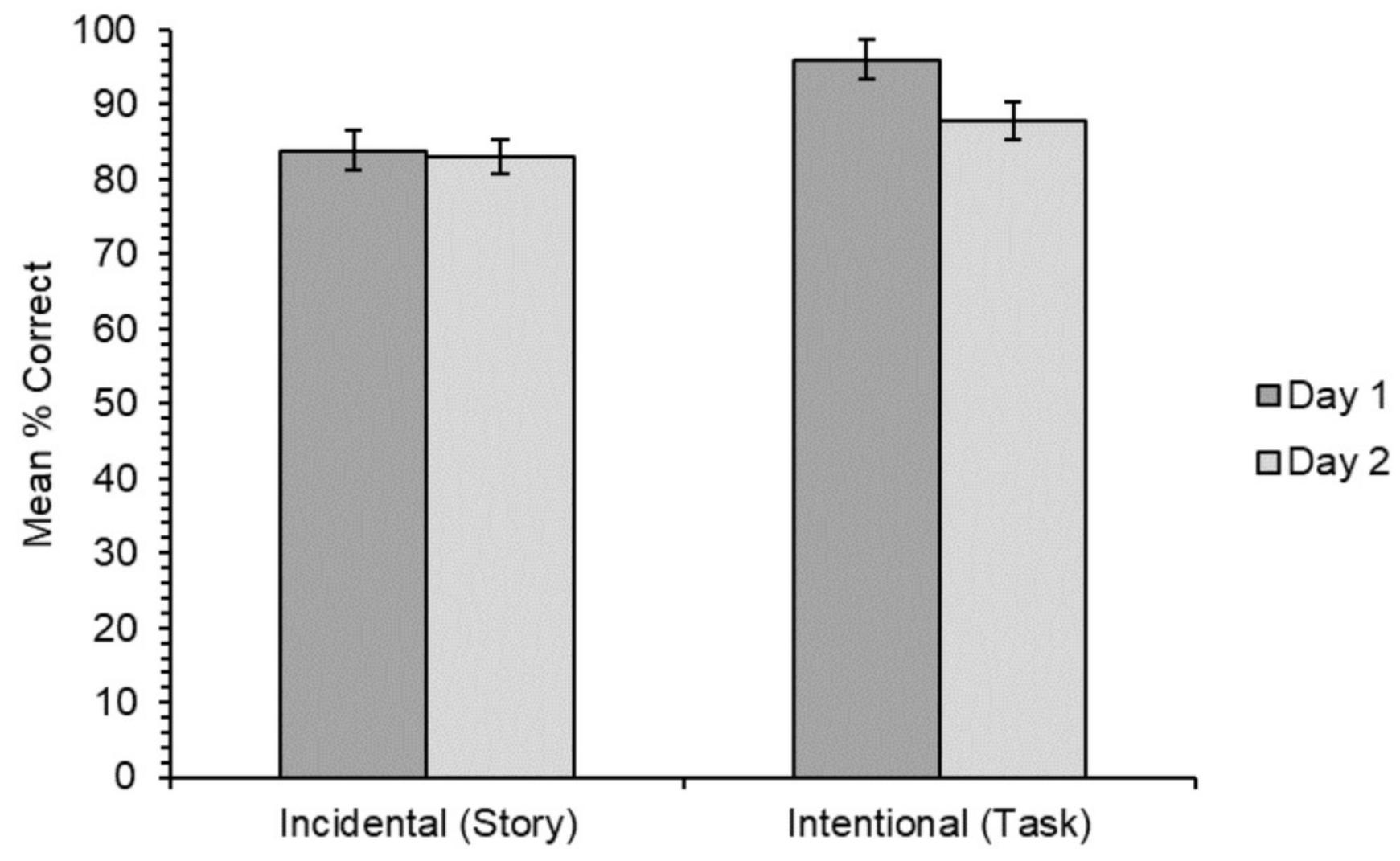


Figure 3

Experiment 2. Mean percentage of correct responses in the cued recall test for each learning condition and for the three different test types in the experiment.

Error bars show standard error of the means adjusted for the within-participant design (Cousineau, 2005).

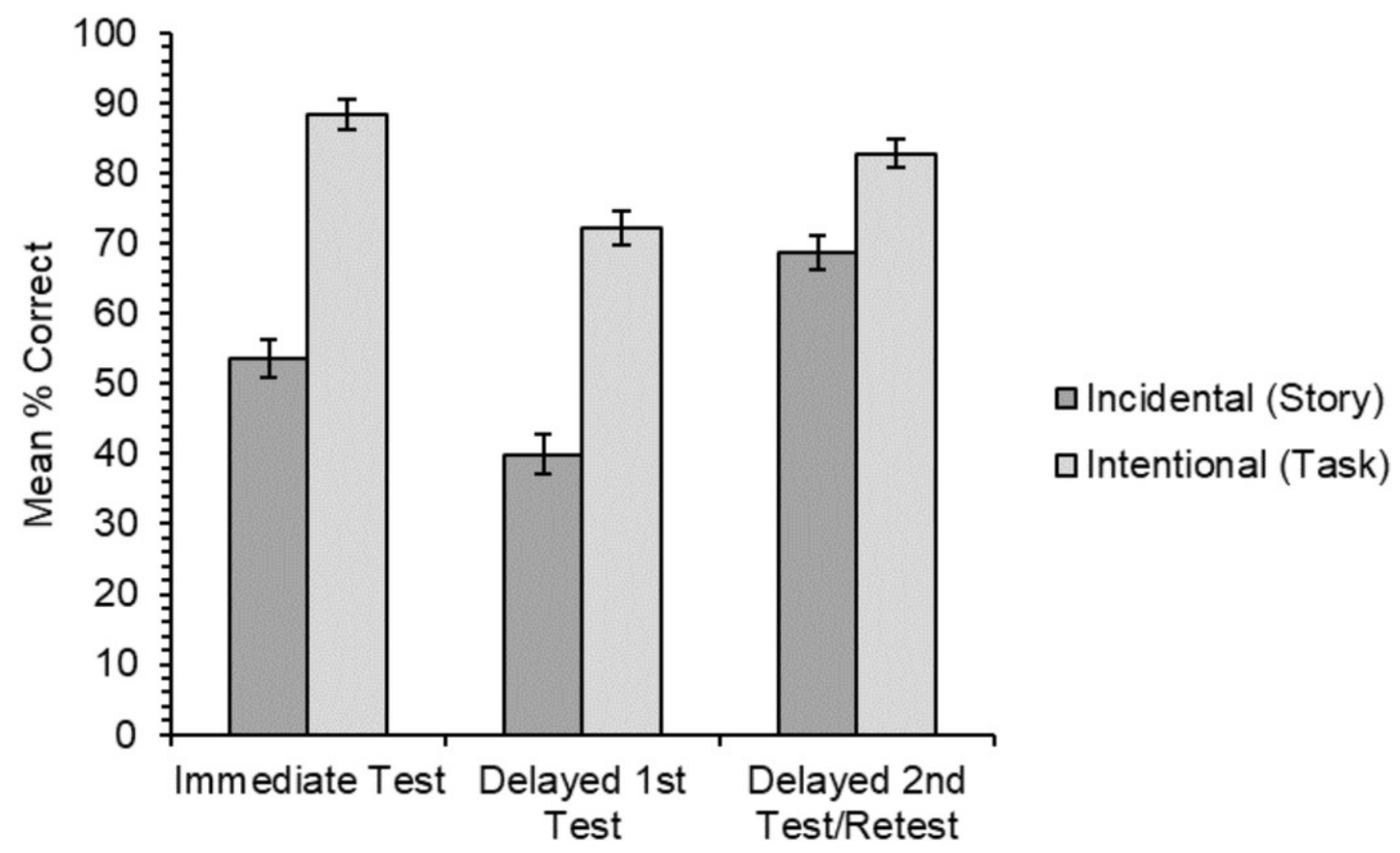




\section{Table $\mathbf{1}$ (on next page)}

Table 1. Results for the linear mixed effects model analyses for the cued recall test in Experiment 2 showing the main analyses and the different levels of follow-up analyses.

Test results reported are for likelihood ratio tests comparing the full model to models with each fixed factor/interaction of interest removed in turn. 


\begin{tabular}{|c|c|c|c|}
\hline Fixed effect or interaction & $\chi^{2}$ & $d f$ & $p$ \\
\hline \multicolumn{4}{|l|}{ 1. Main analysis $(\alpha=.05)$} \\
\hline Learning condition (Incidental vs. Intentional) & 34.83 & 1 & $<.001$ \\
\hline Test type (Immediate vs. Delayed $1^{\text {st }}$ vs. Delayed $2^{\text {nd }}$ ) & 25.78 & 2 & $<.001$ \\
\hline Learning order (First task vs. Second task) & 2.50 & 1 & .114 \\
\hline Learning condition $\mathrm{x}$ Test type & 13.86 & 2 & $<.001$ \\
\hline Learning condition $\mathrm{x}$ Learning order & 0.09 & 1 & .760 \\
\hline Test type $\mathrm{x}$ Learning order & 9.24 & 2 & .010 \\
\hline Learning condition $\mathrm{x}$ Test type $\mathrm{x}$ Learning order & 3.23 & 2 & .199 \\
\hline
\end{tabular}

2. Follow-up pairwise comparisons of the different levels of Test type $(\alpha=.017)$

\begin{tabular}{llll} 
Immediate vs. Delayed $1^{\text {st }}$ tests & 19.99 & 1 & $<.001$ \\
Delayed $1^{\text {st }}$ vs. Delayed $2^{\text {nd }}$ tests & 18.83 & 1 & $<.001$ \\
Immediate vs. Delayed 2 $2^{\text {nd }}$ tests & 0.89 & 1 & .345 \\
\hline
\end{tabular}

3. Follow-up pairwise comparisons of $2 \times 2$ interactions between pairs of levels of Test type and the two Learning conditions $(\alpha=.017)$

Learning condition x Immediate vs. Delayed $2^{\text {nd }}$ tests $\quad 16.24 \quad 1 \quad<.001$

Learning condition x Immediate vs. Delayed $1^{\text {st }}$ tests $\quad 2.29 \quad 1 \quad 130$

Learning condition x Delayed $1^{\text {st }}$ vs. Delayed $2^{\text {nd }}$ tests $\quad 2.97 \quad 1 \quad \quad 085$

4. Simple effects analyses of differences between levels of Test type within the two Learning conditions $(\alpha=.008)$

Immediate vs. Delayed $1^{\text {st }}$ tests for Incidental learning $\quad 5.88 \quad 1 \quad \begin{array}{lll}0 & 015\end{array}$ 


\begin{tabular}{|c|c|c|}
\hline Delayed $1^{\text {st }}$ vs. Delayed $2^{\text {nd }}$ tests for Incidental learning & 15.27 & 1 \\
\hline Immediate vs. Delayed $2^{\text {nd }}$ tests for Incidental learning & 14.59 & 1 \\
\hline Immediate vs. Delayed $1^{\text {st }}$ tests for Intentional learning & 18.27 & 1 \\
\hline Delayed $1^{\text {st }}$ vs. Delayed $2^{\text {nd }}$ tests for Intentional & 8.39 & 1 \\
\hline
\end{tabular}

$\begin{array}{llll}\text { Immediate vs. Delayed } 2^{\text {nd }} \text { tests for Intentional learning } & 4.25 & 1 & .039\end{array}$

Exploratory analyses: Pairwise comparisons of $2 \times 2$ interactions between pairs of levels of Test type and the two Learning orders $(\alpha=.017)$

Learning order x Delayed $1^{\text {st }}$ vs. Delayed $2^{\text {nd }}$ tests $\quad \begin{array}{llll}7.12 & 1 & .008\end{array}$

$\begin{array}{llll}\text { Learning order x Immediate vs. Delayed 2 } 2^{\text {nd }} \text { tests } & 0.12 & 1 & .729\end{array}$

Learning order x Immediate vs. Delayed $1^{\text {st }}$ tests $\quad \begin{array}{llll}5.15 & 1 & .023\end{array}$

Exploratory analyses: Simple effects analyses of differences between levels of Test type within the two Learning orders $(\alpha=.025)$

First task vs. Second task for Immediate test $2.25 \quad 1 \quad .134$

First task vs. Second task for Delayed $1^{\text {st }}$ test $2.04 \quad 1 \quad .154$

First task vs. Second task for Delayed $2^{\text {nd }}$ test

$4.91 \quad 1 \quad .027$


Figure 4

Experiment 2. Mean percentage of correct responses in the multiple-choice test for each learning condition and for the three different test types in the experiment.

Note that the results from the immediate test are not comparable to those from the two delayed test types due to an underlying difference in test difficulty. Error bars show standard error of the means adjusted for the within-participant design (Cousineau, 2005).

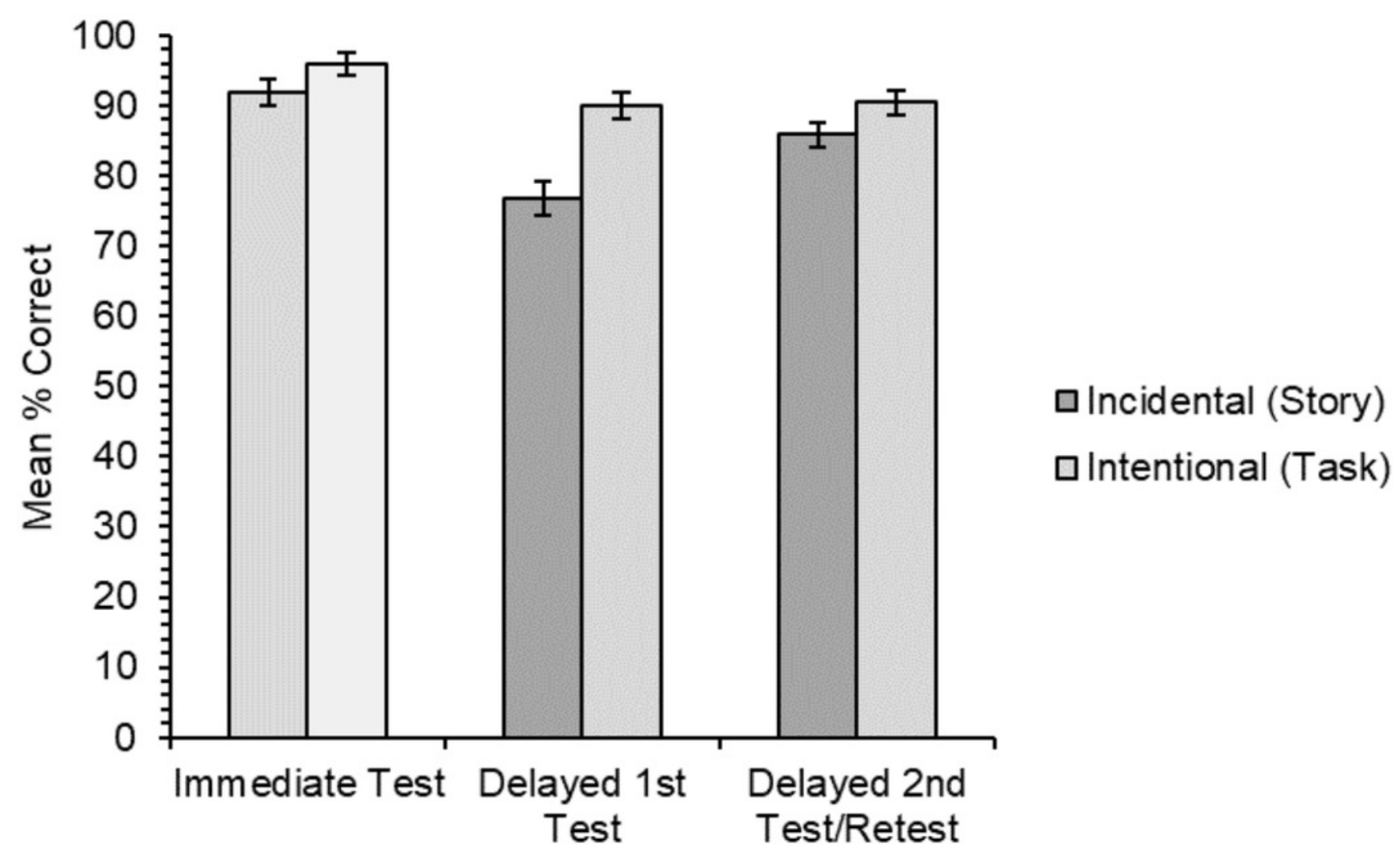


Figure 5

Experiment 3. Mean percentage of correct responses in the cued recall test measured at the delayed test for participants whose immediate test was cued recall, and for those whose immediate test was multiple-choice when items were or were not previously te

Error bars show standard error of the means adjusted for the within-participants factor of whether items were or were not previously tested (Cousineau, 2005).

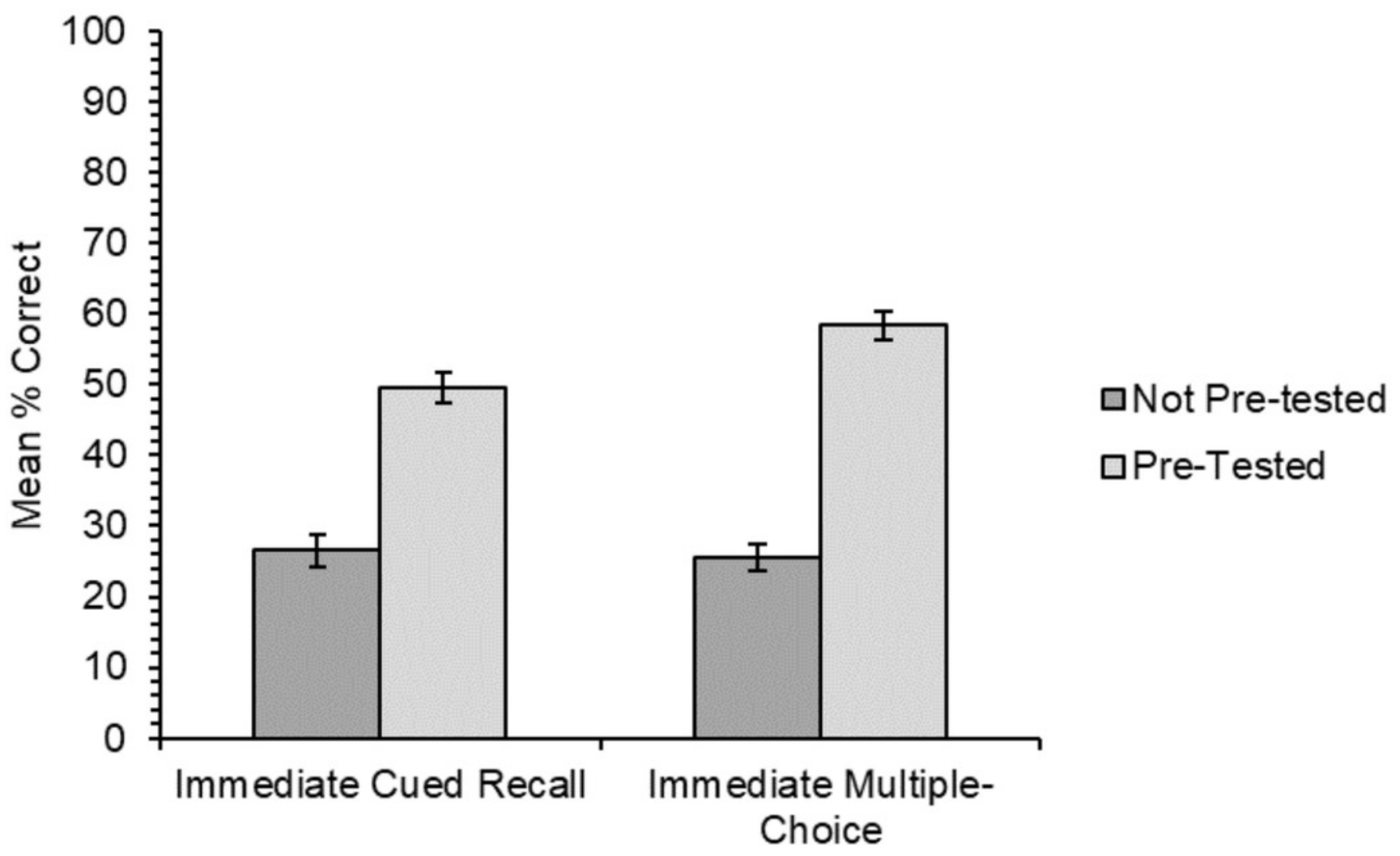




\section{Figure 6}

Experiment 3. Mean percentage of correct responses in the multiple-choice test measured at the delayed test for participants whose immediate test was cued recall, and for those whose immediate test was multiple-choice, when items were or were not previous

Error bars show standard error of the means adjusted for the within-participants factor of whether items were or were not previously tested (Cousineau, 2005).

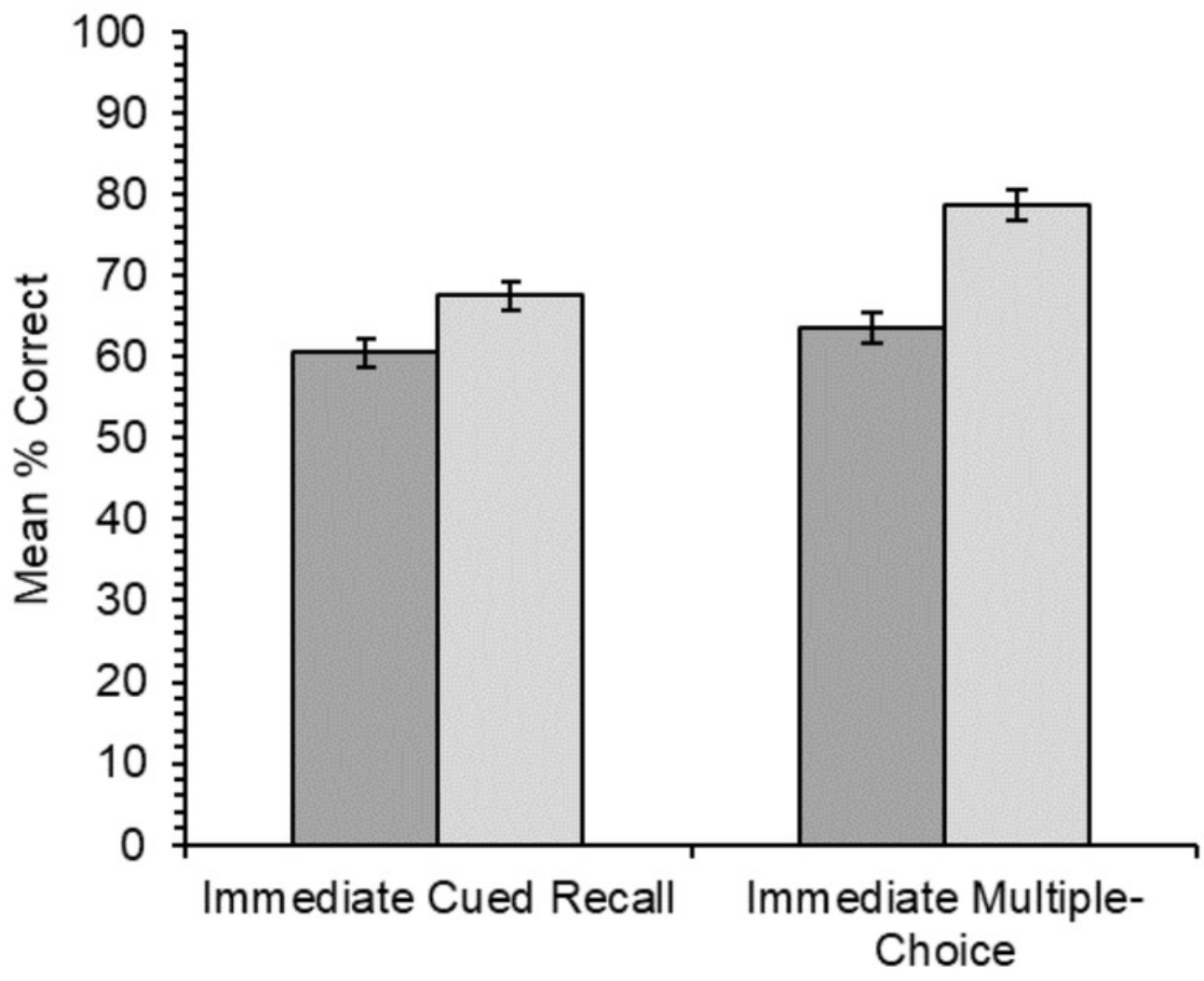

$\square$ Not Pre-tested 口Pre-Tested 